\title{
Innovation, Reallocation and Growth
}

\section{Citation}

Acemoglu, Daron, Ufuk Akcigit, Nicholas Bloom, and William R. Kerr. "Innovation, Reallocation and Growth." Harvard Business School Working Paper, No. 13-088, April 2013. (NBER Working Paper Series, No. 18993, April 2013.)

\section{Permanent link}

http://nrs.harvard.edu/urn-3:HUL.InstRepos:10646424

\section{Terms of Use}

This article was downloaded from Harvard University's DASH repository, and is made available under the terms and conditions applicable to Open Access Policy Articles, as set forth at http:// nrs.harvard.edu/urn-3:HUL.InstRepos:dash.current.terms-of-use\#OAP

\section{Share Your Story}

The Harvard community has made this article openly available.

Please share how this access benefits you. Submit a story.

\section{Accessibility}




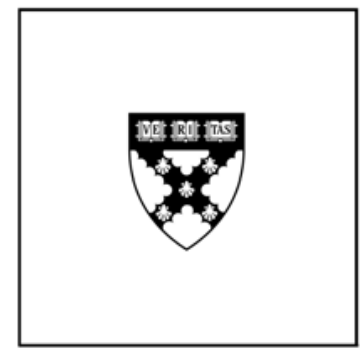

\section{Innovation, Reallocation and Growth}

Daron Acemoglu

Ufuk Akcigit

Nicholas Bloom

William Kerr

\section{Working Paper}

\section{3-088}

April 12, 2013 


\title{
Innovation, Reallocation and Growth*
}

\author{
Daron Acemoglu ${ }^{\dagger} \quad$ Ufuk Akcigit $^{\ddagger} \quad$ Nicholas Bloom $^{\S}$ William Kerr $₫$
}

April 12, 2013

\begin{abstract}
We build a model of firm-level innovation, productivity growth and reallocation featuring endogenous entry and exit. A key feature is the selection between high- and low-type firms, which differ in terms of their innovative capacity. We estimate the parameters of the model using detailed US Census micro data on firm-level output, $R \& D$ and patenting. The model provides a good fit to the dynamics of firm entry and exit, output and R\&D, and its implied elasticities are in the ballpark of a range of micro estimates. We find industrial policy subsidizing either the $\mathrm{R} \& \mathrm{D}$ or the continued operation of incumbents reduces growth and welfare. For example, a subsidy to incumbent R\&D equivalent to $5 \%$ of GDP reduces welfare by about $1.5 \%$ because it deters entry of new high-type firms. On the contrary, substantial improvements (of the order of $5 \%$ improvement in welfare) are possible if the continued operation of incumbents is taxed while at the same time R\&D by incumbents and new entrants is subsidized. This is because of a strong selection effect: $R \& D$ resources (skilled labor) are inefficiently used by low-type incumbent firms. Subsidies to incumbents encourage the survival and expansion of these firms at the expense of potential high-type entrants. We show that optimal policy encourages the exit of low-type firms and supports R\&D by high-type incumbents and entry.
\end{abstract}

JEL No. E2, L1, O31, O32 and O33

Keywords: entry, growth, industrial policy, innovation, R\&D, reallocation, selection.

\footnotetext{
${ }^{*}$ We thank participants in Kuznetz Lecture at Yale University and in seminars at New York University, Federal Reserve Bank of Minneapolis, North Carolina State University, Bank of Finland, University of Pennsylvania, University of Toronto Growth and Development Conference, AEA 2011 and 2012, NBER Summer Institute Growth Meeting 2012, CREI-MOVE Workshop on Misallocation and Productivity, Federal Reserve Bank of Philadelphia, and Microsoft for helpful comments. This research is supported by Harvard Business School, Innovation Policy and the Economy forum, Kauffman Foundation, National Science Foundation, and University of Pennsylvania. Douglas Hanley provided excellent research assistance in all parts of this project. The research in this paper was conducted while the authors were Special Sworn Status researchers of the US Census Bureau at the Boston Census Research Data Center (BRDC). Support for this research from NSF grant ITR-0427889 [BRDC] is gratefully acknowledged. Research results and conclusions expressed are the authors' and do not necessarily reflect the views of the Census Bureau or NSF. This paper has been screened to ensure that no confidential data are revealed.

${ }^{\dagger}$ MIT, CEPR and NBER

${ }^{\ddagger}$ University of Pennsylvania and NBER

${ }^{\S}$ Stanford University, NBER and CEPR

"Harvard University, Bank of Finland, and NBER
} 


\section{Introduction}

Industrial policies that subsidize (often large) incumbent firms, either permanently or when they face distress, are pervasive. Many European governments have supported large firms with the aim of creating national champions (Owen, 2000; Lerner, 2012). The majority of regional aid also ends up going to larger firms because they tend to be more effective at obtaining subsidies (Criscuolo et al., 2012). This industrial aid has grown substantially with the onset of the recent recession, as exemplified by the US bailout of General Motors and Chrysler in the Fall of 2008, which cost an estimated $\$ 82$ billion (Rattner, 2010). The European Union also spent massive amounts on its bailouts, with $€ 1.18$ trillion (equivalent to $9.6 \%$ of EU GDP) going to aid in 2010 alone (European Commission, 2011).

Despite the ubiquity of such policies, their effects are poorly understood. They may encourage incumbents to undertake greater investments, increase productivity and protect employment (e.g., Aghion et al., 2012). But they may also reduce economic growth by discouraging innovation by both entrants and incumbents and slowing down reallocation. The reallocation implications of such policies may be particularly important because the existing literature attributes as much as $70 \%$ or $80 \%$ of productivity growth in the United States to reallocation - exit of less efficient and entry of more efficient firms. ${ }^{1}$

An analysis of industrial policy subsidizing incumbents first needs to distinguish between different types of subsidies (e.g., subsidies to the operation of incumbents vs. those to incumbent R\&D). More importantly, it also needs to build upon an empirical and theoretical framework with several crucial dimensions of firm-level heterogeneity and firm behavior. In particular: (1) this framework must incorporate meaningful firm heterogeneity in productivity, innovation behavior, employment growth, and exit behavior (including potentially between small and large, and young and old firms); (2) it must combine innovation by incumbents and by entrants; (3) it must link reallocation of resources to innovation; and (4) it must include an exit margin for less productive firms (so that the role of subsidies that directly or indirectly prevent exit can be studied).

The first part of the paper develops such a framework and provides a characterization of equilibrium innovation and reallocation dynamics. The second part of the paper estimates the parameters of the model and conducts policy experiments intended to shed light on the impact of different types of industrial policy.

\footnotetext{
${ }^{1}$ Foster, Haltiwanger and Krizan (2000 and 2006) report that reallocation, broadly defined to include entry and exit, accounts for around $50 \%$ of manufacturing and $90 \%$ of US retail productivity growth. Within this, entry and exit account for about half of reallocation in manufacturing and almost all of the reallocation in retail. These figures probably underestimate the full contribution of reallocation since entrants' prices tend to be below industry average leading to a downward bias in their estimated TFP (Foster, Haltiwanger and Syverson, 2008). As a result the contribution of reallocation to aggregate productivity growth in the US across all sectors is probably substantially higher. Numerous papers looking at productivity growth in other countries also find a similarly important role for differences in reallocation in explaining differences in aggregate productivity growth. For example, Hsieh and Klenow (2009), Bartelsman, Haltiwanger and Scarpetta (2009) and Syverson (2011) discuss how variations in reallocation across countries play a major role in explaining differences in productivity levels.
} 
Our model builds on the endogenous technological change literature (e.g., Romer, 1990, Aghion and Howitt, 1992, Grossman and Helpman, 1991) and in particular, on Klette and Kortum's (2004) and Lentz and Mortensen's (2008) models of firm-level innovation, and also incorporates major elements from the reallocation literature (e.g., Hopenhayn, 1992, 2012, Hopenhayn and Rogerson, 1993, Ericson and Pakes, 1995, Restuccia and Rogerson, 2008, Guner et al. 2008, Hsieh and Klenow, 2009, Jones, 2011, Peters, 2012). Incumbents and entrants invest in R\&D in order to improve over (one of) a continuum of products. Successful innovation adds to the number of product lines in which the firm has the best-practice technology (and "creatively" destroys the lead of another firm in this product line). Incumbents also increase their productivity for non-R\&D related reasons (i.e., without investing in $R \& D$ ). Because operating a product line entails a fixed cost, firms may also decide to exit some of the product lines in which they have the best-practice technology if this technology has sufficiently low productivity relative to the equilibrium wage. Finally, firms have heterogeneous (high and low) types affecting their innovative capacity - their productivity in innovation. This heterogeneity introduces a selection effect as the composition of firms is endogenous, which will be both important in our estimation and central for understanding the implications of different policies. We assume that firm type changes over time and that low-type is an absorbing state (i.e., high-type firms can transition to low-type but not vice versa), which is important for accommodating the possibility of firms that have grown large over time but are no longer innovative.

This selection effect is shaped by two opposing forces: on the one hand, old firms will be positively selected because low-type firms are more likely to exit endogenously (e.g., Jovanovic, 1982, Hopenhayn, 1992); on the other hand, old firms will be negatively selected because more of them will have transitioned to the low-type status. The balance of these two forces will determine whether young (and small) firms are more innovative and contribute more to growth. This feature also implies that the key dimension of reallocation in our model is that of skilled labor used for $\mathrm{R} \& \mathrm{D}$ and for fixed operating costs. In particular, skilled labor is allocated for R\&D across firms with different types and between $\mathrm{R} \& \mathrm{D}$ and operating costs.

Our focus on the reallocation (and misallocation) of $R \& D$ inputs is different from that of much of the literature, which emphasizes the reallocation of production input. This focus is motivated by the importance of innovation activities for economic growth. Our model separates R\&D and production inputs both for greater transparency and because the margin between R\&D and nonR\&D activities for production workers seems secondary for the issues at hand.

Despite the various dimensions of firm-level decisions, heterogeneity, and selection effects, which will prove important in our estimation and quantitative exercises, we show that the model is tractable and that much of the equilibrium can be characterized in closed form (conditional on the wage rate, which does not admit a closed-form solution). This equilibrium characterization then enables the estimation of the model's parameters using simulated method of moments.

The data we use for estimation come from the Census Bureau's Longitudinal Business Database 
and Census of Manufacturers, the National Science Foundation's Survey of Industrial Research and Development, and the NBER Patent Database. We design our sample around innovative firms that are in operation during the 1987-1997 period. As discussed in greater detail below, the combination of these data sources and our sample design permits us to study the full distribution of innovative firms, which is important when considering reallocation of resources for innovation, and to match the model's focus on R\&D-based firms. Our model closely links the growth dynamics of firms to their underlying innovation efforts and outcomes, and we quantify the reallocation of resources necessary for innovation. ${ }^{2}$ Our sample contains over $98 \%$ of the industrial R\&D conducted in the US during this period.

Figure 1A: Transition Rates

Figure 1B: R\&D Intensity

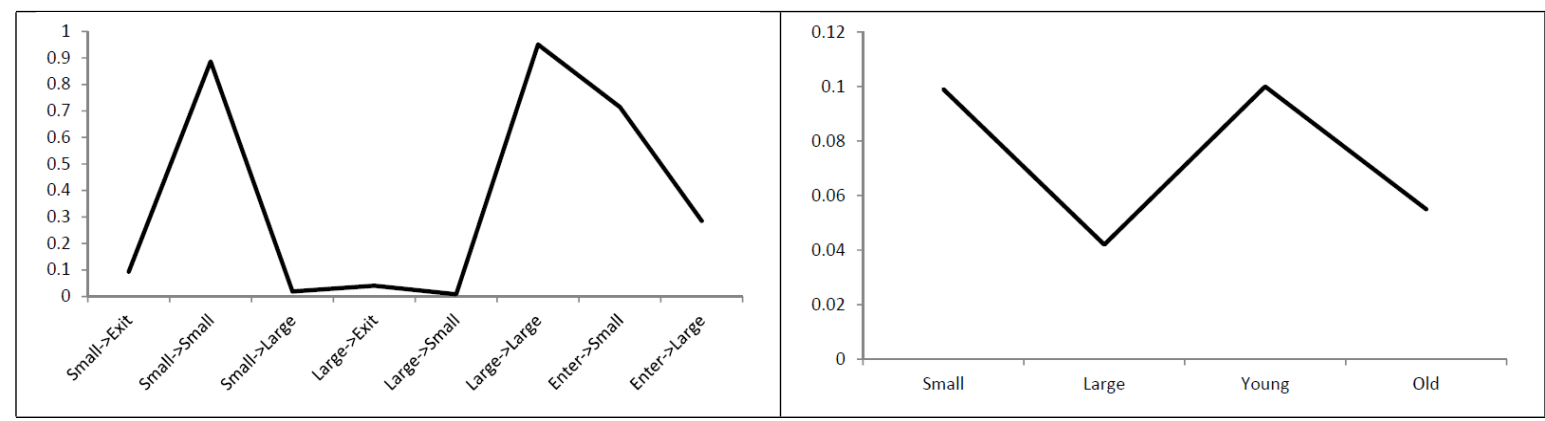

Figure 1C: Sales Growth

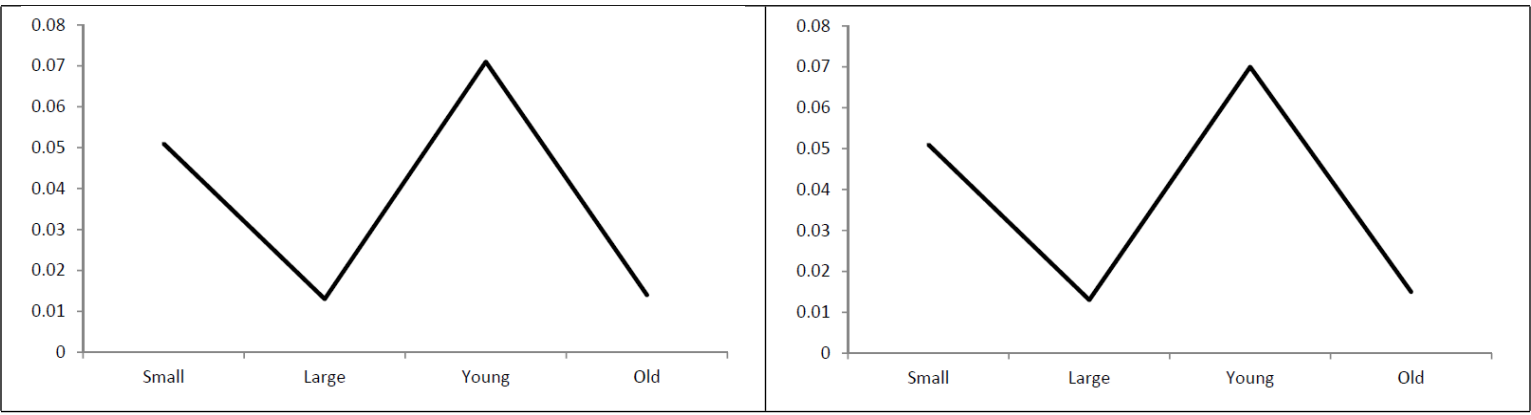

Figures 1A-D summarize some specific aspects of the aforementioned firm-level heterogeneity which we use in our estimations below. They show R\&D expenditures by shipments, employment growth and exit rates between small, large, young and old firms. Small and large are distinguished by the median employment counts in the sample by year; young and old are split by whether or not the firm is ten years old. A noteworthy pattern within our sample is that small and young firms are both more R\&D intensive and grow more. ${ }^{3}$ Thus, industrial policies that discourage

\footnotetext{
${ }^{2}$ Non-innovative firms, by definition, do not participate in this process nor do they compete for these resources; hence having firms that do not conduct innovation in the sample would create a mismatch between both our focus and our model and the data. Though it would be possible to add another selection margin to the model whereby non-innovative firms choose to transition into innovation, this appears fairly orthogonal to our focus, and we view it as an area for future work.

${ }^{3}$ Given our sample just described, these relationships are conditional on engaging in innovation (R\&D or patenting), and are in line with other works in this area, which also find that, conditional on innovation, small and young firms are more innovative and more productive/radical in research. See, for example, Acs and Audretsch (1988, 1990),
} 
the reallocation of resources towards newer firms might indeed be costly in that they slow the movement of R\&D resources from less efficient innovators (struggling incumbents) towards more efficient innovators (new firms).

We compute 21 moments capturing key features of firm-level R\&D behavior, shipments growth, employment growth and exit, and how these moments vary by size and age. We use these moments to estimate the 12 parameters of our model. The model performs well and matches these 21 moments qualitatively (meaning that the rankings by firm age and size are on target) and on the whole also quantitatively. In addition, we show that a variety of correlations implied by the model (not targeted in the estimation) are similar to the same correlations computed from the data. Finally, we also evaluate the model by comparing the response of innovation to R\&D expenditure and $R \& D$ tax credits in our model to various micro and instrumental-variables estimates in the literature and find that they are in the ballpark of these estimates.

We then use our model to study the effects of various counterfactual policies and gain insights about whether substantial improvements in economic growth and welfare are possible. We first look at the impacts of different types of industrial policies: subsidies to incumbent $\mathrm{R} \& \mathrm{D}$, to the continued operation of incumbents and to entry. The main result here is that all these policies have small effects, and in the case of subsidies to incumbents, these are negative effects both on growth and welfare. For example, a subsidy to incumbent R\&D equivalent to $5 \%$ of GDP reduces growth from $2.24 \%$ to $2.16 \%$ and welfare (in consumption equivalent terms) by about $1.5 \%$. A subsidy equivalent to $5 \%$ of GDP to the continued operation of incumbents reduces growth by exactly the same amount, but welfare by less, by about $0.8 \%$. A subsidy equivalent to $5 \%$ of GDP to entry increases growth and welfare, but again by a small amount (growth increases to $2.32 \%$ and welfare by $0.63 \%) .{ }^{4}$ When we consider subsidies equivalent to $1 \%$ of GDP, all of these numbers are correspondingly smaller.

These small effects might first suggest that the equilibrium of our model is approximately optimal. Though they do indeed reveal that any deviation from optimality is not just related to insufficient R\&D incentives (a typical occurrence in models with endogenous innovation), in reality they mask a very substantial inefficiency in equilibrium originating from the selection effect discussed above. This can be seen in two ways. First, we compute the socially optimal allocation chosen by a planner who controls R\&D investments, and entry and exit decisions of different types of firms. We find that such an allocation would achieve a $3.8 \%$ growth rate per annum (relative to $2.24 \%$ in equilibrium) and a $6.46 \%$ increase in welfare. The social planner achieves this by forcing low-type incumbents to exit at a very high rate and reducing their $\mathrm{R} \& \mathrm{D}$, and increasing

Akcigit (2010), Akcigit and Kerr (2010), Cohen and Klepper (1996a,b), Corsino, Espa and Micciolo (2011), Lee and Sung (2005) and Tether (1998). See also Haltiwanger et al. 2013) on the role of small and young firms in job creation.

${ }^{4}$ We report the implications of subsidies equivalent to $5 \%$ of GDP to make the numbers easier to understand. This underscores the limited magnitude of thehow small the growth and welfare implications of industrial policy. For comparison, note that $\mathrm{R} \& \mathrm{D}$ tax credits to incumbents, the main form of $\mathrm{R} \& \mathrm{D}$ subsidy in the United States, was about $\$ 8$ billion in 2007, 2008 and 2009 (see http://www.irs.gov/uac/SOI-Tax-Stats-Corporation-Research-Credit), so about $0.06 \%$ of GDP. 
the $R \& D$ of high-type incumbents, thus inducing a strong selection from low-type firms where the productivity of skilled labor is low to high-type firms. Second, we look at the effect of using optimal levels of incumbent R\&D, entrant and operation subsidy/tax. We find that with all three, or just with taxes on continued operation of incumbents and subsidies to incumbent R\&D, growth can be increased to about $3.11 \%$ and welfare can be increased by almost $5 \%$. This can be achieved by having a huge tax on the continued operation of incumbents ombined with a modest subsidy to incumbent R\&D (between 12 and 17\%). Such a policy strongly leverages the selection effect just like what the social planner was able to achieve directly. In particular, the high tax on the continued operation of incumbents encourages exit, but much more so for low-type firms, and the incumbent R\&D becomes effectively directed towards high-type firms (since the low-type ones are exiting). If allowed, optimal policy also subsidizes entrants, but this is fairly marginal (about 6\%, equivalent to about $1 \%$ of GDP). Though entry and incumbent R\&D play pivotal roles, it turns out to be much better to support these by freeing resources from inefficient, low-type incumbents rather than subsidizing entry or incumbent $R \& D$ directly (and this is the reason why the incumbent R\&D subsidy by itself was ineffective).

We also show that these conclusions are robust to a range of variations. First, they are very similar if we impose the elasticity of innovation to R\&D from some of the micro estimates rather than estimating it by simulated method of moments. Second, they are similar if we shut down non-R\&D productivity growth. Third, they are also fairly similar when we make the entry margin much more inelastic, which would be the case, for example, if there were a fixed or limited supply of potential entrants.

Overall, our policy analysis leads to a number of new results (relative to the literature and beliefs and practices in policy circles). First, industrial policy (support to existing firms and industries) is damaging to growth and welfare, and at best ineffective. Second, the equilibrium is inefficient, but in contrast to other models of endogenous innovation, this cannot be rectified by $R \& D$ subsidies. Third, the allocation of resources and growth can be significantly improved by exploiting the selection effect, which is only weakly utilized in equilibrium. This involves encouraging the reallocation of R\&D resources (skilled labor) from low-type incumbents to high-tech incumbents and entrants, and if done effectively, it can increase growth and welfare by a significant amount.

Our paper is related to a number of different literatures. First, it bridges the works focusing on reallocation (e.g., Foster et al. 2000, 2006 and 2008) which take productivity growth and innovation as exogenous and the parallel literature focusing on innovation (e.g., Romer 1990, Aghion and Howitt 1992, Grossman and Helpman 1991, Jones 1995) that does not examine reallocation. Second, it builds on the prior micro-to-macro innovation literature pioneered by Klette and Kortum (2004) and Lentz and Mortensen (2008). We extend this work in a number of important ways, in particular by introducing endogenous exit and time variation in the innovative capacity of firms. We also depart from all previous work in this area in terms of the questions we pose (in particular, the impact of industrial policy on selection and innovation) and the detailed estimation of the 
model on microdata on innovation and reallocation. Finally, our paper is related to the literature on the effects of industrial policies on innovation, R\&D and growth. Goolsbee (1998), Romer (2001) and Wilson (2009) suggest that R\&D subsidies may mainly increase the wages of inelastic inputs (such as R\&D workers) rather than innovation, while Akcigit, Hanley and Serrano-Velarde (2012) argue that R\&D subsidies may be ineffective when other complementary investments, such as basic science, are not also subsidized. Our findings, instead, show that these policies tend to be ineffective when they fail - as they often do - to generate a positive selection across firm types.

The rest of the paper is organized as follows. Section 2 presents the model. Section 3 describes our data and quantitative framework. Section 4 presents our quantified parameter estimates, assesses the model's fit with the data, and provides validation tests. Section 5 examines the impact of counterfactual policy experiments on the economy's innovation and growth. Section 6 reports the results from a number of robustness exercises. The last section concludes, while Appendix A contains some of the proofs omitted from the text, and Appendix B, which is available online, contains additional proofs and results.

\section{Model}

\subsection{Preferences and Final Good Technology}

Our economy is in continuous time and admits a representative household with the following CRRA preferences

$$
U_{0}=\int_{0}^{\infty} \exp (-\rho t) \frac{C(t)^{1-\vartheta}-1}{1-\vartheta} d t
$$

where $\rho>0$ is the discount factor and $C(t)$ is a consumption aggregate, with price normalized to 1 throughout without loss of generality. The consumption aggregate is given by

$$
C(t)=\left(\int_{\mathcal{N}(t)} c_{j}(t)^{\frac{\varepsilon-1}{\varepsilon}} d j\right)^{\frac{\varepsilon}{\varepsilon-1}}
$$

where $c_{j}(t)$ is the consumption of product $j$ at time $t, \varepsilon>1$ is the elasticity of substitution between products, and $\mathcal{N}(t) \subset[0,1]$ is the set of active product lines at time $t$. The reason why not all products are active at each point in time will be made clear below.

We assume that the economy is closed, and because R\&D and production costs are in terms of labor, we have $c_{j}(t)=y_{j}(t)$, where $y_{j}(t)$ is the amount of product $j$ produced at time $t$. This also implies that aggregate output (GDP) is equal to aggregate consumption, or

$$
Y(t)=C(t)
$$

There are two types of labor in the economy, skilled and unskilled. Unskilled workers are used in the production of the active products (total labor demand denoted by $L^{P}$ ), while skilled workers perform R\&D functions (total labor demand $L^{R D}$ ) and are also employed to cover the (fixed) costs 
of operations, such as management, back-office functions and other non-production work (total labor demand $L^{F}$ ). In particular, we assume that the operation of each product, as well as the operation of each potential entrant, requires $\phi>0$ units of skilled labor.

The representative household has a fixed skilled labor supply of measure $L^{S}$ and an unskilled labor supply of measure 1, both supplied inelastically. The labor market clearing condition then equates total labor demand to labor supply for each type of labor:

$$
L^{P}=1 \text { and } L^{F}+L^{R D}=L^{S} .
$$

With this specification, the representative household maximizes its utility (1) subject to the flow budget constraint

$$
\dot{A}(t)+C(t) \leq r(t) A(t)+w^{u}(t)+L^{S} w^{s}(t),
$$

and the usual no-Ponzi condition, where $A(t)=\int_{\mathcal{N}(t)} V_{j}(t) d j$ is the asset position of the representative household, $r(t)$ is the equilibrium interest rate on assets, and $w^{s}(t)$ and $w^{u}(t)$ denote skilled and unskilled wages respectively. In what follows, we focus on stationary equilibria and drop the time subscripts when this causes no confusion.

\subsection{Intermediate Good Production}

Intermediate good (product) $j$ is produced by the monopolist who has the best (leading-edge) technology in that product line, though a single monopolist can own multiple product lines and can produce multiple intermediate goods simultaneously.

At any given point in time, there are two different sets of firms: $(i)$ a set of active firms $\mathcal{F}$ which own at least one product line; and (ii) a set of potential entrants of measure $m$ which do not currently own any product line but invest in R\&D for innovation.

Consider firm $f \in \mathcal{F}$ that has the leading-edge technology in product $j$. We assume that, once it hires $\phi$ units of skilled labor for operation, this firm has access to a linear technology in product line $j$ of the form

$$
y_{f, j}=q_{f, j} l_{f, j},
$$

where $q_{f, j}$ is the leading-edge technology of firm $f$ in intermediate good $j$ (which means that firm $f$ has the best technology for this intermediate good), and $l_{f, j}$ is the number of workers it employs for producing this good.

Let us denote by $\mathcal{J}_{f}$ the set of active product lines where firm $f$ has the leading-edge technology and chooses to produce, and by $n_{f}$ the cardinality of this set, and also define

$$
\mathcal{Q}_{f} \equiv\left\{q_{f, j_{1}}, q_{f, j_{2}}, \ldots, q_{f, j_{n}}\right\}
$$

as the set of productivities of firm $f$ in product lines in the set $\mathcal{J}_{f}$. In what follows, we will drop the $f$ subscript when this causes no confusion; for example, we refer to $q_{f, j}$ as $q_{j}$. 
With this notation, equation (3) implies that the marginal cost of production in line $j$ is simply $w^{u} / q_{j}$. Since all allocations will depend on the productivity of a product relative to the unskilled wage, we define the relative productivity of a product with productivity $q$ as

$$
\hat{q} \equiv \frac{q}{w^{u}}
$$

We also define the productivity index of the economy as

$$
Q \equiv\left(\int_{\mathcal{N}} q_{j}^{\varepsilon-1} d j\right)^{\frac{1}{\varepsilon-1}}
$$

\subsection{Firm Heterogeneity and Dynamics}

Firms differ in terms of their innovative capacities. Upon successful entry into the economy, each firm draws its type $\theta \in\left\{\theta^{H}, \theta^{L}\right\}$, corresponding to one of two possible types high $(H)$ and low $(L)$. We assume:

$$
\operatorname{Pr}\left(\theta=\theta^{H}\right)=\alpha \text { and } \operatorname{Pr}\left(\theta=\theta^{L}\right)=1-\alpha,
$$

where $\alpha \in(0,1)$ and $\theta^{H}>\theta^{L}>0$. Firm type impacts innovation as described below. We assume that while low-type is an absorbing state, high-type firms transition to low-type at the exogenous flow rate $\nu>0$.

In addition to the transition from high to low type, each firm is also subject to an exogenous destructive shock at the rate $\varphi$. Once a firm is hit by this shock, its value declines to zero and it exits the economy.

Innovation by incumbents is modeled as follows. When firm $f$ with type $\theta_{f}$ hires $h_{f}$ workers for developing a new product, it adds one more product into its portfolio at the flow rate

$$
X_{f}=\theta_{f}^{\gamma} n_{f}^{\gamma} h_{f}^{1-\gamma}
$$

where $\gamma \in(0,1)$ and $n_{f}$ is the number of product lines that firm $f$ owns in total. Suppressing the $f$ subscripts, this implies the following cost function for $\mathrm{R} \& \mathrm{D}$

$$
C(x, n, \theta)=w^{s} n x^{\frac{1}{1-\gamma}} \theta^{-\frac{\gamma}{1-\gamma}} \equiv w^{s} n G(x, \theta),
$$

where $x \equiv X / n$ is the "innovation intensity" (innovation effort per product) and $G(x, \theta) \equiv$ $x^{\frac{1}{1-\gamma}} \theta^{-\frac{\gamma}{1-\gamma}}$, defined in (6), denotes the skilled labor requirement for a firm with innovative capacity $\theta$ to generate a per product innovation rate of $x$.

We assume that research is undirected across product lines, meaning that firms do not know ex ante upon which particular product line they will innovate. This implies that their expected return to $R \& D$ is the expected value across all product lines $j \in[0,1]$.

When a firm innovates over an active product line $j$, it increases the productivity of this product line $j$ by $q_{j} \lambda$. That is,

$$
q_{j}(t+)=(1+\lambda) q_{j}(t)
$$


where $t+$ refers to the instant after time $t$, and $\lambda>0$ is the proportional incremental improvement in technology due to innovation. If the firm innovates over an inactive product line, it draws a new relative productivity from the (stationary) equilibrium distribution $F(\hat{q})$.

In addition to productivity growth driven by $\mathrm{R} \& \mathrm{D}$, we also allow for non-R\&D activity growth both to capture the fact that firms generate productivity growth for reasons unrelated to their research expenditures and to allow for the possibility that there are potential advantages for incumbents (e.g., due to their size) even if they do not perform R\&D. We model this in the following tractable manner: each active firm receives a positive innovation shock at the rate $\varrho$ per (active) product line, and following this, it adds one of the inactive product lines into its portfolio (crucially, the likelihood of this innovation is independent of $\mathrm{R} \& \mathrm{D}$ effort). The productivity of the product lines is determined through a new draw from $F(\hat{q})$.

\subsection{Entry and Exit}

There is a large supply of potential entrants. In equilibrium, a measure $m$ of those will be active. To do so, an entrant needs to hire $\phi$ units of skilled labor and has access to an R\&D technology $G\left(x^{\text {entry }}, \theta^{E}\right)$, where the function $G$ was defined in (6) above and specifies the number of skilled workers necessary for generating an innovation rate of $x^{\text {entry }}$. This specification implies that a potential entrant has access to an $\mathrm{R} \& \mathrm{D}$ technology that an incumbent with innovative capacity $\theta^{E}$ and a single active product would have had. Summarizing, an entrant wishing to achieve an innovation rate of $x^{\text {entry }}$ would need to hire

$$
h^{e n t r y}=\phi+G\left(x^{e n t r y}, \theta^{E}\right)
$$

skilled workers.

Upon entry, firms draw their incumbent type $\theta \in\left\{\theta^{H}, \theta^{L}\right\}$ and the productivity of the product they will produce as specified above.

This description implies the following free-entry condition:

$$
\max _{x^{e n t r y} \geq 0}\left\{-w^{s} \phi+x^{e n t r y} \mathbb{E} V^{e n t r y}(\hat{q}, \theta)-w^{s} G\left(x^{e n t r y}, \theta^{E}\right)\right\}=0,
$$

where $\mathbb{E} V^{\text {entry }}($.$) is the expected value of entry (and the expectation is over the relative productivity$ $\hat{q}$ of the single product the successful entrants will obtain and firm type $\theta \in\left\{\theta^{H}, \theta^{L}\right\}$ which will be realized upon successful entry). The maximization in (8) determines the R\&D intensity of an entrant, conditional on paying the fixed cost of operations (in terms of $\phi$ units of skilled labor). So long as the maximized value of this expression is positive, there will be further entry, and if it is negative, there will be less entry. Thus in equilibrium, the number (measure) of entrants, $m$, has to adjust so as to set this maximized value to zero. ${ }^{5}$ Given the resulting number of entrants, the total entry rate is $X^{e n t r y} \equiv m x^{e n t r y}$.

\footnotetext{
${ }^{5}$ This is unless we are at a corner with $m=0$. For this reason, (8) should have been in complementary slackness form, but since our focus is always on an equilibrium with positive growth and entry, we have written it as an equality.
} 
Exit (of products and firms) has three causes:

1. Creative destruction, which will result from innovation by other firms replacing the leadingedge technology in a particular product line.

2. Exogenous destructive shock at the rate $\varphi>0$.

3. Obsolescence, which will result from the endogenous exit of firms from product lines that are no longer sufficiently profitable relative to the fixed cost of operation.

Due to the second and third factors, the measure of inactive product lines, $\Phi^{n p}$, will be positive.

\subsection{Value Functions}

We normalize all the growing variables by $Q(t)$ to keep the stationary equilibrium values constant. Let us denote the normalized value of a generic variable $X$ by $\tilde{X}$. Let $\tau$ denote the average creative destruction rate which is endogenously determined in the economy. Then the stationary equilibrium value function for a low-type firm can be written as

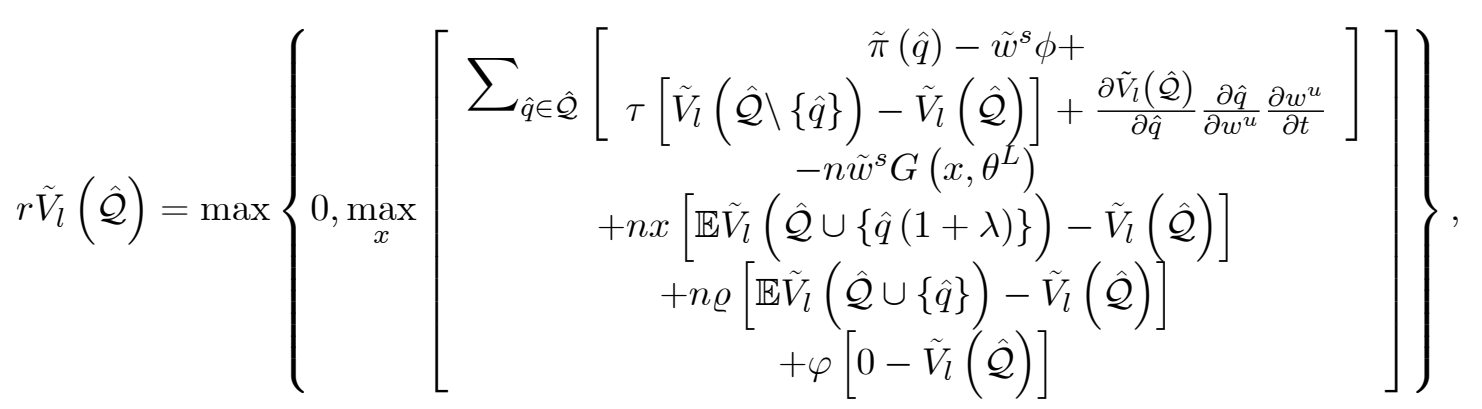

where $\hat{\mathcal{Q}} \cup\left\{\hat{q}_{j^{\prime}}\right\}$ denotes the new portfolio of the firm after successfully innovating in product line $j^{\prime}$. Similarly $\hat{\mathcal{Q}} \backslash\left\{\hat{q}_{j}\right\}$ denotes the loss of a product with technology $\hat{q}_{j}$ from firm $f$ 's portfolio $\hat{\mathcal{Q}}$ due to creative destruction.

The value function (9) can be interpreted as follows. Given discounting at the rate $r$, the lefthand side is the flow value of a low-type firm with a set of product lines given by $\hat{\mathcal{Q}}$. The right-hand side includes the components that make up this flow value. The first line (inside the summation) includes the instantaneous operating profits, minus the fixed costs of operation, plus the change in firm value if any of its products gets replaced by another firm through creative destruction at the rate $\tau$, plus the change in firm value due to the the increase in the economy-wide wage. This last term accounts for the fact that as the wage rate increases, the relative productivity of each of the products that the firm operates declines. The second line subtracts the R\&D expenditure by firm $f$. The third line expresses the change in firm value when the low-type firm is successful with its $R \& D$ investment at the rate $x$. The fourth line indicates the change in value when a positive innovation shock arrives at the rate $\varrho$. The last line shows the change in value when the firm has to exit due to an exogenous destructive shock at the rate $\varphi$. 
Similarly, we can write the value function of a high-type firm,

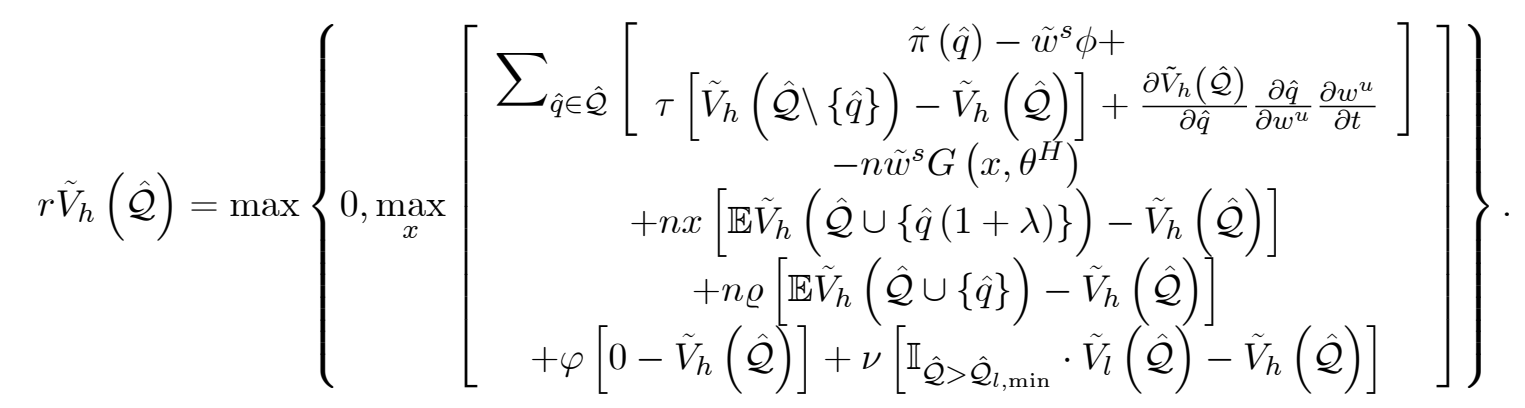

The major difference from (9) is in the last line, where we incorporate the possibility of a transition to a low-type status at the rate $\nu$. The remaining terms have the same interpretation as (9).

The next lemma shows that the value of each firm can be expressed as the sum of the franchise values of each of their product lines, defined as the net present discounted value of profits from a product line (as we will see these franchise values depend on the type of the firm). This decomposition enables us to derive an expression for the value functions in terms of a differential equation for the franchise value of each product line.

Lemma 1 The value function of a $k \in\{h, l\}$ type firm takes an additive form

$$
\tilde{V}_{k}(\hat{\mathcal{Q}})=\sum_{\hat{q} \in \hat{\mathbf{q}}} \Upsilon^{k}(\hat{q})
$$

where $\Upsilon^{k}(\hat{q})$ is the franchise value of a product line of relative productivity $\hat{q}$ to a firm of type $k$. Moreover, $\Upsilon^{k}(\hat{q})$ is strictly increasing and firms follow a cutoff rule for their obsolescence decision such that

$$
\iota^{k}(\hat{q})\left\{\begin{array}{l}
=1 \text { if } \hat{q}>\hat{q}_{k, \min } \\
=0 \text { if } \hat{q}<\hat{q}_{k, \min } \\
\in[0,1] \text { otherwise }
\end{array}\right.
$$

Proof. See the Appendix.

\subsection{Equilibrium}

The household's intertemporal choice delivers the following standard Euler equation

$$
\frac{\dot{C}}{C}=\frac{r-\rho}{\vartheta}
$$

Next we turn to the intermediate good producers' problem. The specification in (2) generates the following demand for product $j$

$$
p_{j}=C^{\frac{1}{\varepsilon}} c_{j}^{-\frac{1}{\varepsilon}}, \forall j \in[0,1] .
$$

Then the monopolist firm $f$ solves the following profit maximization for product line $j$

$$
\pi\left(q_{j}\right)=\max _{c_{j}}\left\{\left(C^{\frac{1}{\varepsilon}} c_{j}^{-\frac{1}{\varepsilon}}-\hat{q}_{j}^{-1}\right) c_{j}\right\}
$$


which delivers the price and demand for intermediate good $j$ as

$$
p_{j}=\frac{\varepsilon}{(\varepsilon-1) \hat{q}_{j}} \text { and } c_{j}=\left[\frac{\varepsilon-1}{\varepsilon} \hat{q}_{j}\right]^{\varepsilon} C .
$$

Therefore the equilibrium profits are

$$
\pi\left(\hat{q}_{j}\right)=\frac{\hat{q}_{j}^{\varepsilon-1}}{\varepsilon-1}\left[\frac{\varepsilon-1}{\varepsilon}\right]^{\varepsilon} C .
$$

Utility maximization by consumers yields

$$
1=\left[\int_{\mathcal{N}} p_{j}^{1-\varepsilon} d j\right]^{\frac{1}{1-\varepsilon}} .
$$

Substituting $c_{j}$ from (12) into the production function (2), the unskilled wage rate is

$$
w^{u}=\frac{\varepsilon-1}{\varepsilon} Q,
$$

where $Q$ is given in (4).

The next lemma characterizes the franchise value of a single product line as the solution to a simple differential equation (the solution to which is provided in Proposition 1) and the type of the firm with the best technology in this product line.

Lemma 2 The franchise values of owning a product line of relative productivity $\hat{q}$ by low-type and high-type firms, respectively, are given the following differential equations

$$
\begin{aligned}
(r+\tau+\varphi) \Upsilon^{l}(\hat{q})-\frac{\partial \Upsilon^{l}(\hat{q})}{\partial \hat{q}} \frac{\partial \hat{q}}{\partial w^{u}} \frac{\partial w^{u}}{\partial t} & =\left\{\Pi \hat{q}^{\varepsilon-1}-\tilde{w}^{s} \phi+\Omega^{l}\right\} \text { if } \hat{q}>\hat{q}_{l, \min } \\
\Upsilon^{l}(\hat{q}) & =0 \text { otherwise }
\end{aligned}
$$

and

$$
\begin{aligned}
(r+\tau+\varphi) \Upsilon^{h}(\hat{q})-\frac{\partial \Upsilon^{h}(\hat{q})}{\partial \hat{q}} \frac{\partial \hat{q}}{\partial w^{u}} \frac{\partial w^{u}}{\partial t} & =\left\{\begin{array}{c}
\Pi \hat{q}^{\varepsilon-1}-\tilde{w}^{s} \phi+\Omega^{h}+ \\
\nu\left[\mathbb{I}_{\hat{q}>\hat{q}_{l, \min }} \cdot \Upsilon^{l}(\hat{q})-\Upsilon^{h}(\hat{q})\right]
\end{array}\right\} \text { if } \hat{q}>\hat{q}_{h, \text { min }} \\
\Upsilon^{h}(\hat{q}) & =0 \text { otherwise }
\end{aligned}
$$

where $\Pi \equiv \frac{1}{\varepsilon-1}\left[\frac{\varepsilon-1}{\varepsilon}\right]^{\varepsilon}$, and

$$
\Omega^{k} \equiv \max _{x}\left\{\begin{array}{c}
-\tilde{w}^{s} G\left(x, \theta^{k}\right)+x \mathbb{E} \Upsilon^{k}(\hat{q}(1+\lambda)) \\
+\varrho \mathbb{E} \Upsilon^{k}(\hat{q})
\end{array}\right\}, \text { for } k \in\{L, H\}
$$

is the option value of a $k$-type firm. Moreover, the R\&D policy function of a $k$-type firm is

$$
x^{k}=\theta^{k}\left[\frac{(1-\gamma) \mathbb{E} \Upsilon^{k}(\hat{q}(1+\lambda))}{\tilde{w}^{s}}\right]^{\frac{1-\gamma}{\gamma}} \text { for } k \in\{L, H\} .
$$

Finally, $\hat{q}_{k, \text { min }}$ is given by

$$
\hat{q}_{k, \min }=\left(\frac{\tilde{w}^{s} \phi-\Omega^{k}}{\Pi}\right)^{\frac{1}{\varepsilon-1}} \text { for } k \in\{L, H\} .
$$


Proof. This follows from the proof of Lemma 1.

Intuitively, the franchise value of a firm with relative productivity $\hat{q}$ can be solved out explicitly for the following reasons. First, so long as this product line remains active, the firm receives two returns: a flow of profits depending on $\hat{q}, \Pi \hat{q}^{\varepsilon-1}$, and the option value, denoted by $\Omega^{k}$ for a firm of type $k$. The option value includes an $\mathrm{R} \& \mathrm{D}$ component since the firm can undertake $\mathrm{R} \& \mathrm{D}$ building on the knowledge embedded in this active product line, and it also includes a non-R\&D component since incumbents stochastically acquire new product lines without R\&D investment. While operating this product line, the firm also incurs the fixed cost of operation $\tilde{w}^{s} \phi$. Second, the relative productivity of this product line is declining proportionately at the growth rate of the economy, $g$, reducing profits at the rate $(\varepsilon-1) g$. Third, this product line is replaced by a higher productivity one at the rate $\tau$ and the firm exits for endogenous reasons at the rate $\varphi$, making the effective discount rate $r+\tau+\varphi$. Fourth, if this product line is not replaced or the firm does not exit by the time its relative productivity reaches $\hat{q}_{k \text {,min }}$ (for a firm of type $k$ ), it will be made obsolete, providing a boundary condition for the differential equation. Finally, for high-type firms there is an additional term incorporating the possibility of switching to low-type.

The next proposition provides the solution to these differential equations.

Proposition 1 Let $g$ and $\tilde{w}^{s}$ be the stationary equilibrium growth rate of the economy and the normalized skilled wage rate, respectively. Moreover, let

$$
\digamma_{k}(x) \equiv\left[1-\left(\frac{\hat{q}_{k, \min }}{\hat{q}}\right)^{x}\right]
$$

Then, the franchise value of a product line value with relative productivity $\hat{q}$ for a low-type firm is

$$
\Upsilon^{l}(\hat{q})=\frac{\Pi \hat{q}^{\varepsilon-1}}{\Psi+(\varepsilon-1) g} \digamma_{l}\left(\frac{\Psi+(\varepsilon-1) g}{g}\right)+\frac{\Omega^{l}-\tilde{w}^{s} \phi}{\Psi} \digamma_{l}\left(\frac{\Psi}{g}\right),
$$

where $\Pi \equiv \frac{1}{\varepsilon-1}\left[\frac{\varepsilon-1}{\varepsilon}\right]^{\varepsilon}$ and $\Psi \equiv r+\tau+\varphi$. Similarly, the franchise value of a product line with relative productivity $\hat{q}$ for a high-type firm is

$$
\Upsilon^{h}(\hat{q})=\left\{\begin{array}{l}
\frac{\Pi \hat{q}^{\varepsilon-1}}{\Psi+\nu+(\varepsilon-1) g} \digamma_{h}\left(\frac{\Psi+\nu+(\varepsilon-1) g}{g}\right)-\frac{\tilde{w} \phi-\Omega^{h}}{\Psi+\nu} \digamma_{h}\left(\frac{\Psi+\nu}{g}\right), \text { for } \hat{q} \in\left[\hat{q}_{h, \min }, \hat{q}_{l, \min }\right] \\
\left\{\begin{array}{c}
\frac{\Pi \hat{q}^{\varepsilon-1}}{\Psi+\nu+g(\varepsilon-1)} \digamma_{h}\left(\frac{\Psi+\nu+(\varepsilon-1) g}{g}\right)+\frac{\Omega^{h}-\tilde{w} \phi}{\Psi+\nu} \digamma_{h}\left(\frac{\Psi+\nu}{g}\right) \\
\frac{\Pi \hat{q}^{\varepsilon-1}}{\Psi+(\varepsilon-1) g} \digamma_{l}\left(\frac{\Psi+(\varepsilon-1) g}{g}\right)+\frac{\Omega^{l}-\tilde{w}^{s} \phi}{\Psi} \digamma_{l}\left(\frac{\Psi}{g}\right) \\
-\frac{\Pi \hat{q}^{\varepsilon-1}}{\Psi+\nu+g(\varepsilon-1)} \digamma_{l}\left(\frac{\Psi+\nu+(\varepsilon-1) g}{g}\right)-\frac{\Omega^{l}-\tilde{w}^{s} \phi}{\Psi+\nu} \digamma_{l}\left(\frac{\Psi+\nu}{g}\right)
\end{array}\right\}, \text { for } \hat{q} \geq \hat{q}_{l, \min }
\end{array}\right.
$$

Proof. See the Appendix.

\subsection{Labor Market and Stationary Equilibrium Distributions}

The normalized productivity distribution for type- $k$ firms has a stationary equilibrium distribution function, $F_{k}(\hat{q})$ on $\left[\hat{q}_{k, \min }, \infty\right)$. Let the shares of product lines that belong to two different types of 
firms and inactive product lines be denoted by $\Phi^{h}, \Phi^{l}$ and $\Phi^{n p}$, respectively. Naturally,

$$
\Phi^{h}+\Phi^{l}+\Phi^{n p}=1
$$

Then the labor market clearing condition for unskilled workers is

$$
\int_{\mathcal{N}} l\left(\hat{q}_{j}\right) d j=\left[\frac{\varepsilon-1}{\varepsilon} \frac{1}{w^{u}}\right]^{\varepsilon} C \int_{\mathcal{N}} q_{j}^{\varepsilon-1} d j=1 .
$$

Using (4), (12) and (13), the previous labor market condition gives

$$
Y=C=Q
$$

The labor market clearing for skilled workers, on the other hand, sets the total demand made up of demand from entrants (first term) and demand from incumbents (second term) equal to the total supply, $L^{S}$ :

$$
m\left[\phi+G\left(x^{e n t r y}, \theta^{E}\right)\right]+\int_{\mathcal{N}}\left(\sum_{k \in\{h, l\}} \Phi^{k}\left[h_{k}\left(w^{s}\right)+\phi\right]\right)=L^{S} .
$$

To solve for the labor market clearing condition, we need to characterize the measures of active product lines $\Phi^{k}$ and the stationary equilibrium productivity distributions conditional on firm type. This is done in the next three equations and the next lemma. In each equation, the left-hand side expresses the inflows into product lines of type $h, l$ or $n p$ (which are, respectively, controlled by high-type and low-type firms and inactive) and the right-side expresses the outflows:

$$
\begin{gathered}
\left(X^{\text {entry }} \alpha+\Phi^{h} x^{h}\right)\left(1-\Phi^{h}\right)+\varrho \Phi^{h}=\left\{\begin{array}{c}
\Phi^{h}\left(\nu+\varphi+X^{e n t r y}(1-\alpha)+\Phi^{l} x^{l}\right) \\
+\Phi^{h} \hat{q}_{h, \min } g f_{h}\left(\hat{q}_{h, \text { min }}\right)
\end{array}\right\} \\
\left\{\begin{array}{c}
\left(X^{e n t r y}(1-\alpha)+\Phi^{l} x^{l}\right)\left(1-\Phi^{l}\right) \\
+\Phi^{h} \nu\left[1-F_{h}\left(\hat{q}_{l, \text { min }}\right)\right]+\varrho \Phi^{l}
\end{array}\right\}=\Phi^{l}\left(\varphi+X^{e n t r y} \alpha+\Phi^{h} x^{h}\right)+\Phi^{l} \hat{q}_{l, \min } g f_{l}\left(\hat{q}_{l, \text { min }}\right) \\
\left\{\begin{array}{c}
\varphi\left(1-\Phi^{n p}\right)+\Phi^{h} \hat{q}_{h, \min } g f_{h}\left(\hat{q}_{h, \text { min }}\right) \\
+\Phi^{l} \hat{q}_{l, \text { min }} g f_{l}\left(\hat{q}_{l, \text { min }}\right)+\Phi^{h} \nu F_{h}\left(\hat{q}_{l, \text { min }}\right)
\end{array}\right\}=\varrho\left(1-\Phi^{n p}\right)+\Phi^{n p}\left(X^{e n t r y}+\Phi^{h} x^{h}+\Phi^{l} x^{l}\right)
\end{gathered}
$$

We next express the flow equations that determine the stationary equilibrium productivity distributions for the high-type and low-type product lines (which are different but jointly determined). These distributions ensure that the flows into and out of any interval of productivity are equalized, so that in the stationary equilibrium, these distributions remain invariant.

Lemma 3 The stationary equilibrium (invariant) productivity distributions of active product lines of low-type and high-type firms satisfy the following equations:

$$
g \hat{q} f_{l}(\hat{q})=\left\{\begin{array}{c}
{\left[\begin{array}{c}
g \hat{q}_{l, \text { min }} f_{l}\left(\hat{q}_{l, \text { min }}\right)+(\tau+\varphi)\left[F_{l}(\hat{q})-F_{l}\left(\hat{q}_{l, \text { min }}\right)\right] \\
-\left(\frac{\Phi^{l} x^{l}+(1-\alpha) X^{\text {entry }}}{\Phi^{l}}\right)\left(\Phi^{h} F_{h}\left(\frac{\hat{q}}{1+\lambda}\right)+\Phi^{l} F_{l}\left(\frac{\hat{q}}{1+\lambda}\right)+(1-\Phi) F(\hat{q})\right) \\
-\nu \frac{\Phi^{h}}{\Phi^{l}}\left[F_{h}(\hat{q})-F_{h}\left(\hat{q}_{l, \text { min }}\right)\right]
\end{array}\right] \text { for } \hat{q}_{l, \text { crit }}<\hat{q}} \\
{\left[\begin{array}{c}
g \hat{q}_{l, \text { min }} f_{l}\left(\hat{q}_{l, \text { min }}\right)+(\tau+\varphi)\left[F_{l}(\hat{q})-F_{l}\left(\hat{q}_{l, \text { min }}\right)\right] \\
-\nu \frac{\Phi^{h}}{\Phi^{l}}\left[F_{h}(\hat{q})-F_{h}\left(\hat{q}_{l, \text { min }}\right)\right]
\end{array}\right] \text { for } \hat{q}_{l, \text { min }}<\hat{q} \leq \hat{q}_{l, \text { crit }}}
\end{array}\right.
$$


and

$$
g \hat{q} f_{h}(\hat{q})=\left\{\begin{array}{c}
{\left[\begin{array}{c}
g \hat{q}_{h, \text { min }} f_{h}\left(\hat{q}_{h, \text { min }}\right)+(\tau+\varphi+\nu)\left[F_{h}(\hat{q})-F_{h}\left(\hat{q}_{h, \text { min }}\right)\right] \\
-\left(\frac{\Phi^{h} x^{h}+\alpha X^{e n t r y}}{\Phi^{h}}\right)\left(\begin{array}{c}
\Phi^{h} F_{h}\left(\frac{\hat{q}}{1+\lambda}\right)+\Phi^{l} F_{l}\left(\frac{\hat{q}}{1+\lambda}\right) \\
+(1-\Phi) F(\hat{q})
\end{array}\right)
\end{array}\right] \text { for } \hat{q}_{h, \text { crit }}<\hat{q}} \\
g \hat{q}_{h, \text { min }} f_{h}\left(\hat{q}_{h, \text { min }}\right)+(\tau+\varphi+\nu)\left[F_{h}(\hat{q})-F_{h}\left(\hat{q}_{h, \text { min }}\right)\right] \text { for } \hat{q}_{h, \text { min }}<\hat{q} \leq \hat{q}_{h, \text { crit }}
\end{array}\right.
$$

where $\Phi \equiv \Phi^{h}+\Phi^{l}$ is the measure of active product lines.

Proof. See the Appendix.

\subsection{Aggregate Growth}

Equation (18) shows that aggregate output is equal to the productivity index, $Q$. Thus the growth rate of aggregate output is given by $g=\dot{Q} / Q$. Let us also denote the type-specific productivity indices by $\tilde{Q}_{t}^{k}=\int_{\mathcal{N}_{t}^{s}} q_{j t}^{\varepsilon-1} d j$ where $k \in\{l, h\}$, the ratio of productivity index of low-type to that of high-type active product lines by $\Gamma \equiv \frac{\tilde{Q}^{h}}{\tilde{Q}^{l}}$, and the ratio of the productivity index of inactive product lines to $k$-type productivity index by $\varkappa_{k} \equiv \frac{\Phi^{n p} \mathbb{E}_{F} q_{t}^{\varepsilon-1}}{\tilde{Q}_{t}^{k}}$ (where $k \in\{l, h\}$ ). Then:

Proposition 2 The growth rate of the economy is then equal to

$$
g=\frac{\left(x^{h}+\alpha X^{\text {entry }}\right)\left[(1+\lambda)^{\varepsilon-1}\left(1+\frac{1}{\Gamma}\right)+\varkappa_{h}\right]+\varrho \Phi^{h} \varkappa_{h}-[\tau+\nu+\varphi]}{\varepsilon-1+\hat{q}_{h, \min } f_{h}\left(\hat{q}_{h, \min }\right)},
$$

and $\Gamma$ is the solution to:

$$
\left\{\begin{array}{c}
\left(x^{h}+\alpha X^{\text {entry }}\right)\left[(1+\lambda)^{\varepsilon-1}\left(1+\frac{1}{\Gamma}\right)+\varkappa_{h}\right] \\
+\varrho \varkappa_{h}\left[\Phi^{h}-\Phi^{l} \Gamma\right]
\end{array}\right\}=\left\{\begin{array}{c}
\left(x^{l}+(1-\alpha) X^{\text {entry }}\right)\left[(1+\lambda)^{\varepsilon-1}(1+\Gamma)+\varkappa_{l}\right] \\
+\nu\left[1+\left[1-F_{h}\left(\hat{q}_{l, \min }\right)\right] \Gamma\right] \\
+g\left[\hat{q}_{h, \min } f_{h}\left(\hat{q}_{h, \min }\right)-\hat{q}_{l, \min } f_{l}\left(\hat{q}_{l, \min }\right)\right]
\end{array}\right\} .
$$

Proof. See the Appendix.

The intuition for the growth rate in (25) is as follows. The numerator has the contribution of entrants and different types of incumbent firms to the productivity distribution, and the denominator adjusts for the improvements in productivity distribution due to obsolescence. Note that the growth rate expression is written for high-type firms. There exists an equivalent expression for low-type firms - the equivalence follows since in a balanced growth path, the productivity index of high-type firms $\left(\tilde{Q}^{h}\right)$ and low-type firms $\left(\tilde{Q}^{l}\right)$ must grow at the same rate. This is ensured by the adjustment of productivity ratio $\Gamma$.

Finally we summarize the equilibrium of this economy.

Definition 1 (Stationary Equilibrium) A stationary equilibrium of this economy is a tuple

$$
\left\{y_{j}, p_{j}, l_{j}, \tilde{V}_{l}, \tilde{V}_{h}, \hat{q}_{h, \min }, \hat{q}_{l, \min }, x^{h}, x^{l}, x^{e n t r y}, h^{h}, h^{l}, h^{e n t r y}, m, \Phi^{h}, \Phi^{l}, \Phi^{n p}, F_{l}(\hat{q}), F_{h}(\hat{q}), w^{s}, w^{u}, g, r\right\}
$$


such that $[\mathbf{i}] y_{j}$ and $p_{j}$ maximize profits as in (12) and the labor demand $l_{j}$ satisfies (3); [ii] $\tilde{V}_{l}$ and $\tilde{V}_{h}$ are given by the low-type and high-type value functions in (9) and (10); [iii] $\left(\hat{q}_{h, \text { min }}, \hat{q}_{l, \min }\right)$ satisfy

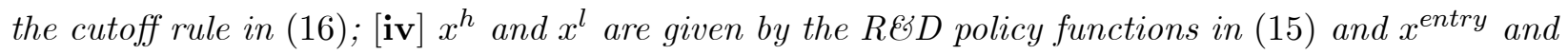
$m$ satisfy the free-entry condition in (8); [v] the skilled worker demands $h^{h}, h^{l}$ and $h^{\text {entry }}$ satisfy (5) and (7); [vi] the product line shares $\left(\Phi^{h}, \Phi^{l}, \Phi^{n p}\right)$ satisfy $(20)-(22)$; [vii] the stationary equilibrium productivity distributions $\left(F_{l}(\hat{q}), F_{h}(\hat{q})\right)$ satisfy (23) and (24); [viii] the growth rate is given by $(25)$; [ix] the interest rate satisfies the Euler equation (11); and $[\mathbf{x}] w^{s}$ and $w^{u}$ are consistent with labor market clearing for unskilled and skilled workers as given by (17) and (19).

Though the stationary equilibrium in this model is a relatively complex object, as we have seen the values for different types of firms can be computed in closed form given the equilibrium wage. There are no closed-form solutions for the equilibrium wage rate and stationary distributions, but these can be computed numerically. We will also use this computation for the simulated method of moments estimation as outlined in Section 3.2.

\subsection{Welfare}

Recall that output and consumption are equal to the productivity index $Q$, so that at the initial date we have $C_{0}=Q_{0}$. The endogenous initial productivity index can be expressed as

$$
Q_{0} \equiv\left(\int_{\mathcal{N}} q_{j 0}^{\varepsilon-1} d j\right)^{\frac{1}{\varepsilon-1}}=\left(\bar{q}_{0} \Phi\right)^{\frac{1}{\varepsilon-1}}
$$

where $\bar{q}_{0}$ denotes the initial average productivity level (specified as the initial condition), and $\Phi \equiv \Phi^{h}+\Phi^{l}$ is the endogenous measure of active product lines. Welfare in the economy depends on this initial productivity index $Q_{0}$ and hence on $\bar{q}_{0}$ and $\Phi$. In the rest of the paper, we normalize the average initial productivity level of all active products lines to 1 , i.e., $\bar{q}_{0}=1$, which thus gives us $C_{0}=Q_{0}=\Phi^{\frac{1}{\varepsilon-1}}$. Then welfare can be obtained as

$$
\begin{aligned}
U_{0}\left(C_{0}, g\right) & =\int_{0}^{\infty} \exp (-\rho t) \frac{C_{t}^{1-\vartheta}-1}{1-\vartheta} d t \\
& =\frac{1}{1-\vartheta} \int_{0}^{\infty}\left[C_{0}^{(1-\vartheta)} e^{-\rho t} e^{(1-\vartheta) g t}-e^{-\rho t}\right] d t \\
& =\frac{1}{1-\vartheta}\left[\frac{\Phi^{\frac{1-\vartheta}{\varepsilon-1}}}{\rho-(1-\vartheta) g}-\frac{1}{\rho}\right]
\end{aligned}
$$

where the first line simply repeats the definition of discounted utility from (1), the second line uses the assumption that we are in stationary equilibrium (thus implying that we are not evaluating welfare implications of transitioning from one stationary equilibrium to another), and the third line solves the integral and uses $C_{0}=\Phi^{\frac{1}{\varepsilon-1}}$.

In comparing welfare in two economies, say with subsidy policies $s_{1}$ and $s_{2}$, and resulting growth rates $g\left(s_{1}\right)$ and $g\left(s_{2}\right)$ and initial consumption levels $C_{0}\left(s_{1}\right)$ and $C_{0}\left(s_{2}\right)$, we compute consumption 
equivalent changes in welfare by considering the fraction of initial consumption $\varpi$ that will ensure the same discounted utility with the new growth rate as with the initial allocation. More formally, $\xi$ is given such that

$$
U_{0}\left(\xi C_{0}\left(s_{2}\right), g\left(s_{2}\right)\right)=U_{0}\left(C_{0}\left(s_{1}\right), g\left(s_{1}\right)\right) .
$$

Note also that the decentralized allocation in this model does not maximize welfare or growth for a variety of reasons. Nevertheless, monopoly markups, in and of themselves, are not a source of inefficiency because they are the same for all products. In models with endogenous technological change, there is typically insufficient $R \& D$ because firms do not appropriate the full value of new innovations (see, e.g., Acemoglu 2008, for a discussion). This channel is also potentially present in the current model and this is the first reason for divergence between the equilibrium and the efficient allocation. In particular, it affects the allocation of skilled workers between R\&D and operations because firms ignore two indirect benefits of innovation: a higher productivity product increases the productivity of firms that innovate over it, and improvements over non-active product lines also benefit from innovation because these build on the existing knowledge stock. ${ }^{6}$ The second reason for the inefficiency of equilibrium is that low productivity firms, especially low productivity low-type firms, remain active too long relative to what the welfare-maximizing social planner would choose. This is because the social planner would take into account that by freeing resources from the fixed cost of operations for these firms, she can increase R\&D, which is not fully internalized by the market because the skilled wage is depressed relative to its social value. These effects imply that policies that increase $R \& D$ and those that shift the composition of firms towards high-type firms will typically increase welfare and growth.

\section{$3 \quad$ Estimation and Quantitative Analysis}

To perform the policy experiments described in the Introduction, we first estimate the parameters of our model using simulated method of moments (SMM). In this section, we describe our data set and estimation procedures, and the next two sections provide our results and policy counterfactual experiments.

\subsection{Data}

We employ the Longitudinal Business Database (LBD), the Census of Manufacturers (CMF), the NSF Survey of Industrial Research and Development (RAD), and the NBER Patent Database (PAT). The LBD and CMF are the backbone for our study. The LBD is a business registry that contains annual employment levels for every private-sector establishment in the US with payroll from 1976 onward. The CMF is conducted every five years and provides detailed records on manufacturing plant and firm operations (e.g., output). Sourced from US tax records and Census

\footnotetext{
${ }^{6}$ Counteracting this, firms also fail to take into account the gains to consumers from increasing the range of active product lines.
} 
Bureau surveys, these micro-records document the universe of establishments and firms, making them an unparalleled laboratory for studying our model of reallocation, entry/exit, and related firm dynamics.

The Survey of Industrial Research and Development (RAD) is the US government's primary instrument for surveying the R\&D expenditures and innovative efforts of US firms. This is an annual or biannual survey conducted jointly by the Census Bureau and NSF. The survey includes with certainty all public and private firms, as well as foreign-owned firms, undertaking over one million dollars of R\&D within the US. The survey frame also sub-samples firms conducting less than the certainty expenditure threshold. The certainty threshold was raised after 1996 to five million dollars of R\&D for future years (before subsequently being lowered after our sample frame). RAD surveys are linked to the LBD's and CMF's operating data through Census Bureau identifiers. These micro-records begin in 1972 and provide the most detailed statistics available on firm-level R\&D efforts. In 1997, 3,741 firms reported positive R\&D expenditures that sum to $\$ 158$ billion. Foster and Grim (2010) provide additional details.

To complement the RAD, we also match patent data into the Census Bureau data. We employ the individual records of all patents granted by the United States Patent and Trademark Office (USPTO) from January 1975 to May 2009. Each patent record provides information about the invention and the inventors submitting the application. Hall et al. (2001) provide extensive details about these data, and Griliches (1990) surveys the use of patents as economic indicators of technology advancement. We only employ patents (i) filed by inventors living in the US at the time of the patent application; and (ii) assigned to industrial firms. In 1997, this group comprised about 77 thousand patents. We match these patent data to the LBD using firm name and location matching algorithms. $^{7}$

Our sample focuses on "continuously innovative" firms. We define a firm as "innovative" if it is conducting R\&D or patenting within the US. Our operating data come from the years 1987, 1992, and 1997 when the CMF is conducted, and the data are specific to those years. We develop our measures of innovation using five-year windows surrounding these CMF years (e.g., 1985-1989 for the $1987 \mathrm{CMF}$ ). These local averages assist with RAD's biannual reporting when it occurs, and they ensure that we include two RAD surveys with the lower certainty threshold for the $1997 \mathrm{CMF}$ group. The local averages also provide a more consistent measure of patent filings, which can be lumpy for firms with few patents. We describe the use of patents in further detail shortly.

The "continuous" part of our sample selection is important and is structured as follows. We only include a firm in our sample if it conducts $R \& D$ or patents during the five-year window surrounding each CMF year in which it is operating (i.e., has positive employment and sales in the CMF). Thus, a firm that is in operation in 1987 and 1992 is included in our sample if it is also conducting R\&D or patents during 1985-1989 and 1990-1994. Similarly, a firm that is in operation in 1992 and 1997

\footnotetext{
${ }^{7}$ Akcigit and Kerr (2010) discuss the R\&D and patent data in much greater detail. The patent matching builds upon the prior work of Balasubramanian and Sivadasan (2011) and Kerr and Fu (2008). See also Kogan et al (2012).
} 
is included in our sample if it is also conducting R\&D or patents during 1990-1994 and 1995-1999. The firm does not need to conduct R\&D or patent in every year of the five-year window, but must do one of the two activities at least once.

This selection process has several features to point out. First, the entrants in our sample (i.e., firms first appearing in the 1992 or $1997 \mathrm{CMF}$ ) will be innovative throughout their lifecycle until the 1995-1999 period. Second, we do not consider switches into innovation among already existing firms. For example, we exclude firms that are present in the 1987 and $1992 \mathrm{CMF}$, patent or conduct R\&D in the 1990-1994 period, but do not patent or conduct R\&D during 1985-1989 (the probability that an existing, non-innovative firm commences R\&D or patenting over the ensuing five years, conditional on survival, is only about 1\%). Third, and on a similar note, we do not include in our sample firms that cease to be innovative but continue in operation. Exits in our economy will be defined over firms that patent or conduct R\&D until they cease to operate.

Finally, our sample does not condition on innovative activity before 1985-1989. Thus, the incumbents in our sample who were in operation prior to the $1987 \mathrm{CMF}$ may have had some point in their past when they did not conduct $R \& D$ or patent. We only require that incumbents be innovative in every period when they are in operation during our sample. This choice allows us to construct a full distribution of innovative firms in the economy, which is important when considering the reallocation of resources for innovation. Of course, this choice is also partly due to necessity as we do not observe the full history of older incumbents. We discuss further below the aggregate implications for reallocation and growth measurement of this design. ${ }^{8}$

We now describe the use of the patenting data. In accordance with our model, the moments below focus on $R \& D$ intensities (i.e., inputs into the innovation production function). We face the challenge that the RAD sub-samples firms conducting less than one million dollars in R\&D. By contrast, the patent data are universally observed. To provide a more complete distribution, we use patents to impute $R \& D$ values for firms that are less than the certainty threshold and not sub-sampled. Thus, our moments combine the R\&D and patent data into a single measure that accords with the model. As the $R \& D$ expenditures in these sub-sampled cases are very low (by definition), this imputation choice versus treating unsurveyed R\&D expenditures as zero expenditures conditional on patenting is not very important.

Overall, our compiled dataset includes innovative manufacturing firms from the years 1987, 1992, and 1997 when the CMF is conducted. A record in our dataset is a firm-year observation that aggregates over the firm's manufacturing establishments. We have 17,055 observations from 9,835 firms. By abstracting from the extensive margin of entry or exit into innovation for continuing firms, all of our moments are consistently defined and well measured in the data. At the same time, our selection procedures provide as complete a distribution of innovative firms as possible,

\footnotetext{
${ }^{8}$ Note that it would have been impossible to build a consistent sample for "ever innovative" firms rather than for continuously innovative firms. To see why, consider keeping all of the past records for firms that conduct R\&D in 1997. In both 1987 and 1992, this approach would induce a mismeasurement of exit propensities and growth dynamics because a portion of the sample will include firms conditioned on survival until 1997.
} 
which is important when considering reallocation. Our sample accounts for $98 \%$ of industrial R\&D conducted during the period. When compared to a single cross-section of data, our sample is slightly more skewed towards larger firms. Specifically, in the average year during our sample period, $22 \%$ of the firms conducting R\&D or patenting have more than 500 employees. In our sample, $31.5 \%$ of observations have more than 500 employees.

Our sample focuses on the reallocation of resources for innovation and thus excludes firms that do not report $R \& D$ or patents, which we define as "non-innovative firms". It is important to place our sample within the overall distribution of economic activity. When including non-innovative firms, our sample accounts for $2.1 \%$ of firms, $2.0 \%$ of firms with fewer than 5000 employees, $48 \%$ of employment, and $65 \%$ of sales within manufacturing. The greater share of employment and sales activity than firm counts is because the great majority of small firms are non-innovative. In a similar manner and due to the link of innovation to growth, our sample accounts for a substantial portion of reallocation occurring. Many small firms are not oriented for growth (e.g., Haltiwanger et al., 2013) and thus play a limited role in reallocation. As one statistic, our sample includes $58 \%$ and $65 \%$ of employment and sales reallocation, respectively, among continuing manufacturing firms between 1987 and 1997. As a second statistic, among firms that were either very small (fewer than 20 employees) or did not exist in 1987, we capture $94 \%$ of those that then grew to $10,000+$ employees by 1997 . We likewise capture $80 \%$ of small firms or new entrants that grow to one billion dollars in sales by 1997 .

Our central moments are firm entry/exit rates, the age and size distribution of firms, transitions across the firm size distribution over time, firm growth rates by age and size, firm innovation intensity by age and size, and entrants' share of employment in the economy. ${ }^{9}$ Size distributions use the median employment in each CMF year to distinguish small and large firms. The age distribution is similarly separated into whether a firm is 0-9 years or 10+ years old. We assign initial ages through when the firm is first observed in the LBD with positive employment. We define moments related to entry/exit, growth, and age-size distribution transitions as changes between CMF years expressed in per annum terms. ${ }^{10}$ Shipments are deflated using the 2009 NBER Productivity Database. ${ }^{11}$

\footnotetext{
${ }^{9}$ Firm age is defined from the birth year of the initial establishment of the firm.

${ }^{10}$ We measure growth rates relative to base years over the five-year period to allow a direct decomposition to per annum terms. These growth rates are winsorized at their $10 \%$ and $90 \%$ values. The patterns are similar when expressing growth relative to the average of base and end years. We then calculate geometric averages over these firm-level growth rates. We winsorize R\&D intensities at their $99.8 \%$ value to be conservative (approximately a 10:1 R\&D to sales ratio).

${ }^{11}$ Prices in industries related to computers and semiconductors behave differently from those in other parts of manufacturing. We find very similar moments when excluding these industries from our moment calculations.
} 


\subsection{Computational Algorithm}

The model can be solved computationally as a fixed point of the following vector of eight aggregate equilibrium variables

$$
\left\{\tilde{w}^{s}, g, \Phi^{h}, \Phi^{l}, \mathbb{E}\left[\Upsilon^{h}(\hat{q})\right], \mathbb{E}\left[\Upsilon^{l}(\hat{q})\right], \mathbb{E}\left[\Upsilon^{h}((1+\lambda) \hat{q})\right], \mathbb{E}\left[\Upsilon^{l}((1+\lambda) \hat{q})\right]\right\}
$$

Our characterization above shows that equilibrium innovation decisions can be determined given these aggregate variables. While the skilled wage $\tilde{w}^{s}$ determines the cost of innovation, the rest of the variables in (27) determine the expected return to innovation. We can solve for the stationary equilibrium by first posing a conjecture for (27), then solving for the individual innovation decisions and then verifying the initial conjecture. Specifically, using the guess for these variables:

1. we compute the innovation intensities $x^{h}$ and $x^{l}$ and option values $\Omega^{h}$ and $\Omega^{l}$, and calculate the functions $\Upsilon^{h}(\hat{q})$ and $\Upsilon^{l}(\hat{q})$ according to Lemma 2 ;

2. using the innovation intensities, we calculate the stationary equilibrium distribution over active/inactive product lines and over values of $\hat{q}$ for those that are active using the flow equations $(20)-(24)$;

3. we check the labor market clearing conditions using the innovation intensities and the above distributions and compute the equilibrium wage rates from (17) and (19), updating $\tilde{w}^{s}$;

4. we update the values for $g, E\left[\Upsilon^{h}(\lambda \hat{q})\right], E\left[\Upsilon^{l}(\lambda \hat{q})\right], E\left[\Upsilon^{h}(\hat{q})\right]$, and $E\left[\Upsilon^{l}(\hat{q})\right]$.

The above system of equations is solved using a Powell hybrid non-linear equation solver. ${ }^{22}$

This procedure gives us (27) as a fixed point and also the stationary equilibrium distributions for $F_{h}(\hat{q})$ and $F_{l}(\hat{q})$. Note that all these variables are determined at the product-line level. We compute firm-level moments by simulating the evolution of a panel of $2^{14}$ firms until they reach approximate stationary equilibrium after 10,000 periods. Each period corresponds to 0.02 of a year hence the total simulation time comes out to 200 years. At each iteration, firms gain and lose products according to the flow probabilities specified in the model.

\subsection{Estimation}

We set the discount rate equal to $\rho=2 \%$, which roughly corresponds to an annual discount factor of $97 \%$, and the inverse of the intertemporal elasticity of substitution to $\vartheta=2$. The remaining 12 parameters, which are listed in Table 1, are estimated with SMM. ${ }^{13}$ We compute the model-implied moments from the simulation strategy described above and compare them to the data-generated moments to minimize

$$
\min \sum_{i=1}^{21} \frac{|\operatorname{model}(i)-\operatorname{data}(i)|}{\frac{1}{2}|\operatorname{model}(i)|+\frac{1}{2}|\operatorname{data}(i)|},
$$

\footnotetext{
${ }^{12}$ For computational reasons, in the intermediate steps where firms draw from the stationary equilibrium relative productivity distribution, we use the best fitting exponential distribution to the distributions derived in the previous iteration.

${ }^{13}$ See McFadden (1989) and Pakes and Pollard (1989) for the statistical properties of the SMM estimator.
} 
where we index each moment by $i$. SMM iteratively searches repeatedly across sets of parameter values in the model until the model's moments are as close as possible to the empirical moments.

Our SMM procedure targets the 21 moments outlined in Table 2, focusing on firm entry, exit, employment and sales growth, and innovation intensity, selected in each case because of their economic importance for the mechanisms of the model. We have a single aggregate moment, the aggregate growth of output per worker in our sample of firms, and we give this moment 5 times the weight of the micro-moments to ensure that we are in the ballpark of matching the aggregate growth in the sample.

\section{Results}

\subsection{Parameter Estimates}

Table 1 reports the parameter estimates we obtain from the SMM procedure. The elasticity of substitution is estimated to be $\varepsilon=1.7$. The estimate of the fixed cost of operation indicates that the ratio of fixed workers to variable production workers is around $3 \%$. The estimates also show that high-type firms are almost 3 times more innovative than low-type firms $\left(\theta^{H} / \theta^{L} \approx 3\right)$. Entrants have a $43 \%$ chance of being a high-type firm $(\alpha=0.43)$, and high-type firms face an annual $9.5 \%$ probability of transitioning to low-type $(\nu=0.095)$. We estimate the share of skilled workers as $7.8 \%$. This share is in line with estimates that we can develop from the data. From the 1990 Census of Populations, $3.9 \%$ of workers in the manufacturing sector have advanced degrees, while $16.2 \%$ of workers have a bachelors' degree or higher (including the 3.9\%). The group of workers that can effectively reallocate between managerial and $R \& D$ roles in firms is likely bounded by these two skill groups, and our estimate of $7.8 \%$ also falls in this range. About $30 \%$ of both groups of workers are engaged in science and engineering occupations at the time of the Census. We discuss the economic interpretation of the remaining parameters below.

Table 1. Parameter Estimates

\begin{tabular}{|r|c|l|c|}
\hline \hline$\#$ & Parameter & Description & Value \\
\hline \hline 1. & $\varepsilon$ & CES & 1.701 \\
\hline 2. & $\phi$ & Fixed cost of operation & 0.032 \\
\hline 3. & $L^{S}$ & Measure of high-skilled workers & 0.078 \\
\hline 4. & $\theta^{H}$ & Innovative capacity of high-type firms & 0.216 \\
\hline 5. & $\theta^{L}$ & Innovative capacity of low-type firms & 0.070 \\
\hline 6. & $\theta^{E}$ & Innovative capacity of entrants & 0.202 \\
\hline 7. & $\alpha$ & Probability of being high-type entrant & 0.428 \\
\hline 8. & $\nu$ & Transition rate from high-type to low-type & 0.095 \\
\hline 9. & $\lambda$ & Innovation step size & 0.148 \\
\hline 10. & $\gamma$ & Innovation elasticity wrt knowledge stock & 0.637 \\
\hline 11. & $\varphi$ & Exogenous destruction rate & 0.016 \\
\hline 12. & $\varrho$ & Non-R\&D innovation arrival rate & 0.012 \\
\hline
\end{tabular}




\subsection{Goodness of Fit}

Table 2 reports the empirical moments that we target and the predicted values from our model. The addition of dashed lines in Figures 2A-D for the model-implied moments provides a graphical depiction (except for moments 20 and 21, which are not shown in these figures).

Table 2. Moment Matching

\begin{tabular}{|l|l|c|c|c|l|c|c|}
\hline \hline$\#$ & Moments & Model & Data & $\#$ & Moments & Model & Data \\
\hline \hline 1. & Firm Exit (small) & 0.086 & 0.093 & 12. & Sales Growth (small) & 0.115 & 0.051 \\
\hline 2. & Firm Exit (large) & 0.060 & 0.041 & 13. & Sales Growth (large) & -0.004 & 0.013 \\
\hline 3. & Firm Exit (young) & 0.078 & 0.102 & 14. & Sales Growth (young) & 0.070 & 0.071 \\
\hline 4. & Firm Exit (old) & 0.068 & 0.050 & 15. & Sales Growth (old) & 0.030 & 0.014 \\
\hline 5. & Trans. from large to small & 0.024 & 0.008 & 16. & R\&D to Sales (small) & 0.097 & 0.099 \\
\hline 6. & Trans. from small to large & 0.019 & 0.019 & 17. & R\&D to Sales (large) & 0.047 & 0.042 \\
\hline 7. & Prob. of small (cond on entry) & 0.539 & 0.715 & 18. & R\&D to Sales (young) & 0.083 & 0.100 \\
\hline 8. & Emp. Growth (small) & 0.063 & 0.051 & 19. & R\&D to Sales (old) & 0.061 & 0.055 \\
\hline 9. & Emp. Growth (large) & -0.007 & 0.013 & 20. & 5 -year Entrant Share & 0.363 & 0.393 \\
\hline 10. & Emp. Growth (young) & 0.040 & 0.070 & 21. & Aggregate growth & 0.022 & 0.022 \\
\hline 11. & Emp. Growth (old) & 0.010 & 0.015 & & & & \\
\hline
\end{tabular}

Figure 2A: Transition Rates

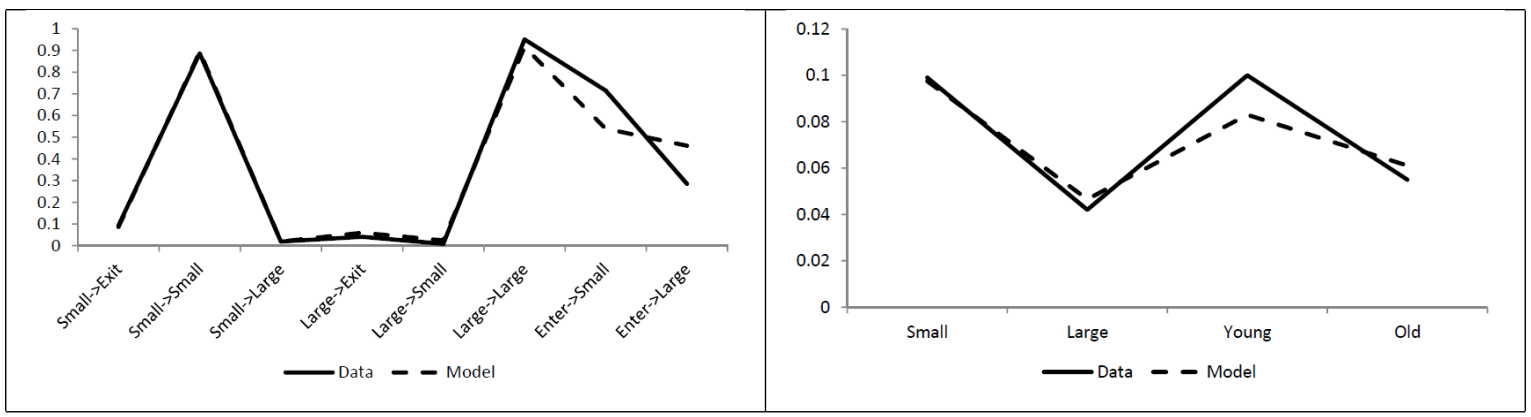

Figure 2C: Sales Growth

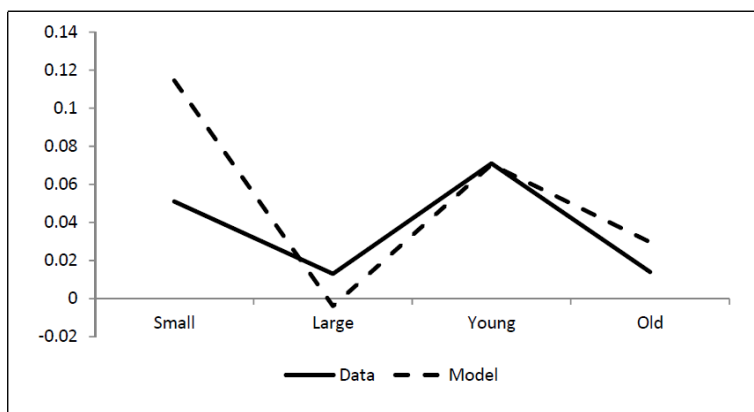

Figure 2B: R\&D Intensity

Figure 2D: Employment Growth

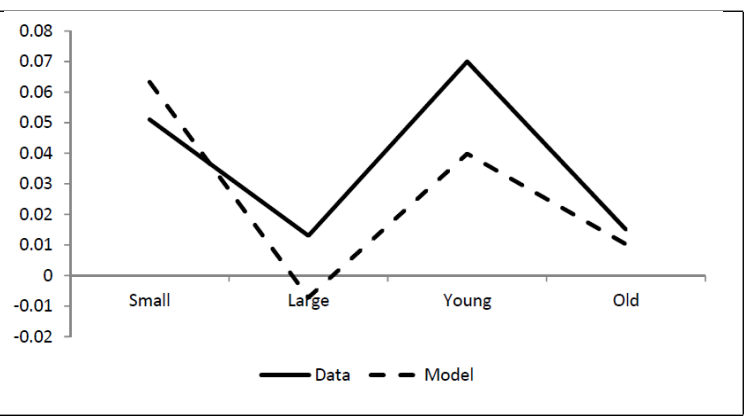

Our estimation procedure generates a relatively good fit for all of the moments. In particular, for most of the moments our model is able to replicate the salient characteristics of data, including lower exit rates for larger and older firms, similar transition rates across firms sizes and entry/exit, similar $\mathrm{R} \& \mathrm{D} /$ sales intensities by firm sizes and ages, and a reasonably good fit for sales and employment growth across different types of firms. Our growth rates for larger firms are slightly negative in the 
model but slightly positive in the data. On the whole, despite the overidentification (matching 21 moments with 12 parameters), the fit is quite good. ${ }^{14}$

\subsection{Decompositions}

The equilibrium productivity growth of $2.24 \%$ can be decomposed into the contribution from entrants and incumbents. Entrants generate $58 \%$ of total productivity growth in the economy. Moreover, we estimate that $77 \%$ of the firm-level growth, conditional on survival, comes from $R \& D$ activities whereas the remaining $23 \%$ is generated through channels not related to $R \& D$, which in our model comes from the non-R\&D arrival rate of new products, $\varrho$.

In any given five-year window, new entrants employ $30 \%$ of production workers. It is worth noticing that innovation in this model generates productivity growth through reallocation of inputs. In equilibrium, $8 \%$ of the workers are reallocated within firms across different product lines, $12 \%$ of the workers are reallocated across different firms, and the remaining $80 \%$ of the workers remain within the same production unit during a five-year period. ${ }^{15}$

Our model has three sources of exit. The estimated model predicts that $81 \%$ of exits happen due to creative destruction, $18 \%$ due to exogenous destructive shocks, and $1 \%$ due to obsolescence. Though obsolescence appears small given the estimated parameter values, we will see that this margin plays an important role in the comparison of the equilibrium to the optimal allocation.

\subsection{Validation Tests}

We validate our model in two ways. The first approach compares non-targeted moments and correlations with those we observe in the data. The second approach compares the results we obtain to micro estimates on the relationship between innovation and $R \& D$ expenditure and the impact of $\mathrm{R} \& \mathrm{D}$ tax credits on innovation. Both approaches provide a type of out-of-sample test of the structure imposed by our model as well as the values of the parameters we have estimated. Reassuringly, we will see that our model performs fairly well in both cases, raising our confidence in the model's ability to provide a good approximation to data and the conclusions that will follow from the policy experiments.

\subsubsection{Non-Targeted Moments}

We begin with several non-targeted moments that Table 3 summarizes. First, we examine the correlation between exit probabilities and R\&D intensity. These correlations are 0.04 and 0.05 in the model and data, respectively. The exit probabilities for firms with low and high R\&D intensities

\footnotetext{
${ }^{14}$ We do not report tests of the overidentifying restrictions for the usual reason for this type of exercise that, given our sample size, standard errors are tiny, and even the most minor deviation from these 21 moments would constitute a rejection of the overidentifying restrictions. At the bottom of this, of course, is the fact that standard errors are computed without allowing for "model misspecification".

${ }^{15}$ For this computation, we assume that when workers are moved from a product line, they are first reallocated within the firm and then across firms.
} 
are 0.32 and 0.34 in the data; these compare to 0.36 and 0.37 in the model. The correlation across firms between R\&D growth and employment growth is 0.19 in the data, but more than twice as high, 0.48 , in the model. This probably reflects the fact that, despite non-R\&D growth, we are not capturing all of the reasons why employment grows at the firm level. This last discrepancy not withstanding, the model performs fairly well with respect to these non-targeted correlations, which is reassuring.

Table 3: Non-targeted Moments

\begin{tabular}{|l|c|c|}
\hline \hline Moments & Model & Data \\
\hline \hline Corr(exit prob, R\&D intensity) & 0.04 & 0.05 \\
\hline Exit prob of low-R\&D-intensive firms & 0.36 & 0.32 \\
\hline Exit prob of high-R\&D-intensive firms & 0.37 & 0.34 \\
\hline Corr(R\&D growth, emp growth) & 0.48 & 0.19 \\
\hline Share firm growth due to R\&D & 0.77 & 0.73 \\
\hline Ratio of top 7.2\% to bottom 92.8\% income & 13.4 & 9.3 \\
\hline
\end{tabular}

The R\&D Survey collects a more detailed questionnaire from selected major R\&D producers that we can use to compare the contribution of R\&D activities to growth in the model to data. ${ }^{16}$ First, the detailed questionnaire contains industry-level R\&D breakouts. This disaggregation allows us to validate the share of growth coming from non-R\&D activities versus R\&D activities. During our sample period, we observe 160 firms that continually conduct R\&D and have industry-level breakouts of their R\&D expenditures. For these firms, the unweighted mean share of employment growth occurring within industries where firms are conducting R\&D is $73 \%$. This estimate closely fits our model's prediction of $77 \%$ of growth coming through R\&D efforts.

Finally we examine the model's prediction for the ratio of skilled to unskilled wages. In the model, skilled workers, corresponding to managerial and science and engineering workers, making up a fraction $7.2 \%(=0.078 /(1+0.078))$ of the population, earn $w^{s}$ and unskilled workers earn $w^{u}$. This corresponds to a ratio of the average income of the top $7.2 \%$ to the average income of the bottom $92.8 \%$ of $w^{s} / w^{u}=13.4$. The corresponding number from the IRS micro income data for all taxpayers in the United States in 2010 is about 9.3 (comparing top 7\% of earners to bottom 93\%). ${ }^{17}$ Even though the upper bound of this range is still about $40 \%$ smaller than our model's prediction, we view this as broadly in the ballpark of this number, even though none of our moments targeted this ratio.

\subsubsection{Comparison to Micro Estimates}

One relevant set of comparable estimates for $\gamma$ can be taken from the literature evaluating the empirical relationship between patents and R\&D expenditures. Griliches (1990) surveyed a prior literature and concluded that the elasticity of patents with respect to $\mathrm{R} \& \mathrm{D}, 1-\gamma$ in our model, is

\footnotetext{
${ }^{16}$ Kerr and $\mathrm{Fu}$ (2008) provide greater details on the selection of firms to complete the long forms.

${ }^{17}$ Statistics from http://www.irs.gov/taxstats/indtaxstats/article/0,id=98123,00.html" IRS Individual Income Tax Statistics. Further details can be found on http://www.inequalityandtaxes.com
} 
between 0.3 and 0.6 which implies $\gamma \in[0.4,0.7]$. Work since that time has continued to find similar results. Using count data models, Blundell, Griffith, and Windmeijer (2002) report an elasticity of 0.5. Hall and Zeidonis (2001) find similar results in a study of the semiconductor industry. We thus conclude that our estimate of $\gamma=0.64$ falls right in the middle of the range of plausible estimates in the literature.

A second approach is to compare our estimate of $\gamma$ to the findings of the studies that considered the response of firms to changes in the cost of $R \& D$ driven by $R \& D$ tax credits. A growing literature examines the impact of $R \& D$ tax credits on the $R \& D$ expenditure of firms. One route uses the variation in the US tax code over time interacted with firms' tax paying and R\&D status to generate time and firm variation in the tax-component of the user cost of R\&D. These studies typically find a tax elasticity of R\&D around unity (e.g., Hall, 1992). A second approach followed by Bloom et al. (2002) exploits time-variation in cross-country R\&D tax credits, while a third approach followed by Wilson (2009) exploits time-variation in cross-state R\&D tax credits in the United States. Estimates in this literature also cluster around unity, as emphasized in the survey paper by Hall and Van Reenen (2000) who state in their conclusion that "a tax price elasticity of around unity is a good ball-park figure". In our model, the R\&D elasticity with respect to scientist wage $w^{s}$ is: ${ }^{18} \frac{\% \Delta R \& D}{\% \Delta w^{s}}=\frac{\gamma-1}{\gamma}$, so the unit elasticity would correspond to $\gamma=0.5$. Our estimate, $\gamma=0.64$, is again in the ballpark, about $20 \%$ higher. In Section 6 , we show that re-estimating our model imposing $\gamma=0.5$ leads to very similar results, particularly in our policy experiments.

\section{$5 \quad$ Policy Experiments and Efficiency}

Our estimated model has an equilibrium growth rate of $2.24 \%$. This is driven by the innovation efforts of the high-type incumbents, low-type incumbents and entrants.

Table 4. Baseline Model

\begin{tabular}{ccccccccccccc}
\hline \hline$x^{\text {entry }}$ & $x^{l}$ & $x^{h}$ & $m$ & $\Phi^{l}$ & $\Phi^{h}$ & $\hat{q}_{l, \min }$ & $\hat{q}_{h, \min }$ & $d r o p_{l}$ & $\frac{w^{s}}{w^{u}}$ & $\tau$ & $g$ & Wel \\
\hline 8.46 & 2.80 & 9.58 & 73.6 & 71.16 & 24.53 & 13.90 & 0.00 & 0.06 & 13.64 & 10.58 & 2.24 & 100 \\
\hline \hline
\end{tabular}

Table 4 above summarizes some of the key endogenous equilibrium objects. In the baseline, hightype incumbents are almost three times as likely to innovate (per product) as low-type firms $\left(x^{h}=\right.$ 0.096 vs. $\left.x^{l}=0.028\right)$. The total entry rate is $6.23 \%\left(\approx x^{e n t r y} \times m=0.085 \times 0.736\right)$. In equilibrium, $71.2 \%$ of the product lines belong to low-type firms and $24.5 \%$ to high-type firms $\left(\Phi^{h}=0.712\right.$ vs. $\left.\Phi^{l}=0.245\right)$. The remaining $4.3 \%$ of product lines are inactive. The average creative destruction in the economy is $10.6 \%(\tau=0.106)$. In addition, the annual obsolescence rate for low-type firms, shown as drop $l$ in the table, is $0.06 \%$, while the obsolescence rate for high-type firms is very close to zero (for this reason and to save space, we do not report it in this and the subsequent tables).

\footnotetext{
${ }^{18}$ To see this, substitute the equilibrium innovation choice (15) into $\mathrm{R} \& \mathrm{D}$ cost function (6) to obtain $R \& D=$ $n \theta^{k}\left(w^{s}\right)^{\frac{\gamma-1}{\gamma}}\left[(1-\gamma) \mathbb{E} \Upsilon^{k}(\hat{q}(1+\lambda))\right]^{\frac{1}{\gamma}}$.
} 
Figure 3 shows the productivity distribution across product lines among high- and low-type firms. An important point to note is that the cutoff productivity for high-type firms is lower since the option value of operating in a product line is higher for them.

Figure 3. Productivity Distributions by Type

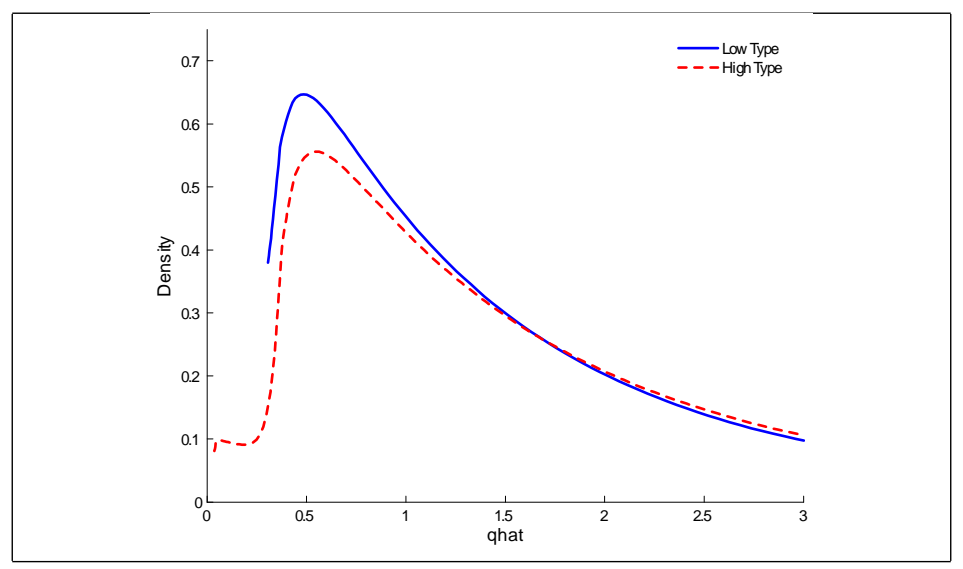

\subsection{Incumbent R\&D Subsidy}

Our first policy counterfactual considers a popular type of industrial policy, subsidizing R\&D efforts of incumbents. In Table 5, we show the results when using 1\% of GDP and then 5\% of GDP for such subsidies. ${ }^{19}$

Table 5. Incumbent R\&D Subsidy

\begin{tabular}{ccccccccccccc}
\hline \hline \multicolumn{10}{c}{ PANEL A. 1\% } & OF GDP $\left(s_{i}=15 \%\right)$ \\
\hline \hline$x^{\text {entry }}$ & $x^{l}$ & $x^{h}$ & $m$ & $\Phi^{l}$ & $\Phi^{h}$ & $\hat{q}_{l, \min }$ & $\hat{q}_{h, \min }$ & $d r o p_{l}$ & $\frac{w^{s}}{w^{u}}$ & $\tau$ & $g$ & Wel \\
\hline 8.46 & 3.05 & 10.56 & 68.10 & 70.74 & 24.96 & 13.40 & 0.00 & 0.06 & 13.88 & 10.55 & 2.23 & 99.86 \\
\hline \hline & & 8 & PANEL & B. 5\% & OF GDP $\left(s_{i}=39 \%\right)$ \\
\hline \hline 8.46 & 3.61 & 13.04 & 49.76 & 69.58 & 25.97 & 13.15 & 0.00 & 0.05 & 14.97 & 10.11 & 2.16 & 98.48 \\
\hline \hline
\end{tabular}

Note: All numbers except wage ratio and welfare are in percentage terms.

Panel A considers a subsidy equivalent to $1 \%$ of GDP, which amounts to a $15 \%$ subsidy on R\&D spending of incumbents. As should have been expected, the $R \& D$ subsidy to incumbents increases their R\&D. In particular, low-type firms increase their innovation rate from $2.80 \%$ to $3.05 \%$, and high-type firms from $9.58 \%$ to $10.56 \%$ - both of these are about $10 \%$ higher than the baseline. However, the overall impact on innovation and growth is less - much less - than this direct effect. This is for two reasons. First, at a given skilled wage, greater incumbent R\&D would increase creative destruction and via this channel discourage entry. Second, and more important, the greater demand for skilled workers from incumbent R\&D increases the skilled wage. In equilibrium, we see that there is a non-trivial (approximately 2\%) increase in the skill wage, from 13.64 to 13.88, and this reduces $R \& D$ by entrants and incumbents sufficiently that overall creative destruction does not

\footnotetext{
${ }^{19}$ Throughout to focus on the economic channels in our model, we assume that these subsidies are not wasted and do not create additional tax distortions.
} 
increase. But the measure of entrants decreases from 0.74 to 0.68 and the total entry rate declines from $8.46 \times 0.74 \approx 6.22$ to $8.46 \times 0.68 \approx 5.76$. The overall result is a decline in growth $2.24 \%$ to $2.23 \%$, and aggregate welfare also decreases by $0.14 \%$ (in consumption equivalent terms).

Panel B shows similar results with a subsidy equivalent to $5 \%$ of GDP. The subsidy now rises to $39 \%$ on R\&D spending of incumbents, and its impact on growth and welfare are more negative. Growth declines from $2.24 \%$ to $2.16 \%$, and welfare declines by $1.5 \%$.

In summary, in contrast to expectations in the literature and in policy circles which, based on the view that there is underinvestment in $R \& D$, consider $R \& D$ subsidies as growth and welfare enhancing, we find that R\&D subsidies to incumbents reduce growth and welfare because they reallocate resources from entrants to incumbents.

\subsection{Subsidy to Operating Costs}

We next consider an industrial policy subsidizing the continued operation of incumbents by subsidizing their fixed costs of operations $w^{s} \phi$, which approximates policies that support large firms that are in economic trouble. ${ }^{20}$ We suppose that the costs of operation by incumbents are subsidized with an amount equivalent to 1\% of GDP (Panel A) and 5\% of GDP (Panel B). The main impact of this change in policy is to lower obsolescence, which was, however, already low. The implications of this subsidy are presented in Table 6.

Table 6. Operation Subsidy

\begin{tabular}{ccccccccccccc}
\hline \hline \multicolumn{10}{c}{ PANEL A. 1\% OF GDP $\left(s_{o}=6 \%\right)$} \\
\hline \hline$x^{\text {entry }}$ & $x^{l}$ & $x^{h}$ & $m$ & $\Phi^{l}$ & $\Phi^{h}$ & $\hat{q}_{l, \min }$ & $\hat{q}_{h, \min }$ & $d r o p_{l}$ & $\frac{w^{s}}{w^{u}}$ & $\tau$ & $g$ & Wel \\
\hline 8.46 & 2.80 & 9.59 & 73.66 & 71.30 & 24.52 & 11.74 & 0.00 & 0.05 & 13.86 & 10.58 & 2.22 & 99.82 \\
\hline \hline \multicolumn{10}{c}{ PANEL B. 5\% } & OF GDP $\left(s_{o}=27 \%\right)$ \\
\hline \hline 8.47 & 2.80 & 9.59 & 73.31 & 71.72 & 24.49 & 4.37 & 0.00 & 0.02 & 14.78 & 10.57 & 2.16 & 99.20 \\
\hline \hline
\end{tabular}

Focusing on Panel A, we see that this policy, which corresponds to a $6 \%$ subsidy to operating costs, discourages obsolescence and increases the share of active product lines (from $95.69 \%$ to $95.81 \%$ ) and raises the demand for skilled workers coming from the fixed costs of operation. The general equilibrium implications of this is a reduction in R\&D for all firms resulting from the higher skilled wage, which is about $2 \%$ higher (13.86 compared to 13.64). However, this subsidy also has a negative selection effect because low-type firms are overrepresented among those at the margin of obsolescence. As a result, the share of low-type firms in the economy increases from $71.16 \%$ to $71.30 \%$ (while the share of high-type firms declines slightly). As part of this, resources are reallocated from more-efficient to less-efficient product lines (since this subsidy directly helps only those product lines near the lower end of the productivity distribution). In consequence, the long-run growth rate declines from $2.24 \%$ to $2.22 \%$, and aggregate welfare declines by $0.18 \%$.

\footnotetext{
${ }^{20}$ Or equivalently, their exit is taxed or some combination thereof. We consider subsidies or taxes on the fixed cost of operations rather than on all costs or on accounting profits, because these alternative policies would also affect markups, partly confounding the main effect we are interested in. All the same, such subsidies or taxes have broadly similar impacts.
} 
The results in Panel B are similar, and the decline in growth is identical to what we saw in Table 5. Interestingly, however, the welfare decline is about half of that in Panel B of Table 5. The main reason for this is that with $5 \%$ of GDP spent on subsidizing operating costs, there is a more sizable expansion of the set of active products (from $95.69 \%$ to $96.21 \%$ ), and having more products active benefits consumers (recall footnote 6). Nevertheless, this benefit is more than outweighed by the selection effect, which is the reason why welfare declines.

In sum, a subsidy to the operating costs of incumbents reduces growth and welfare because it causes a negative selection effect, increasing the share of product lines controlled by low-type firms, as low-type firms tend to benefit more from this subsidy which is directed to low-productivity product lines.

\subsection{Entry Subsidy}

Finally, for comparison, we also consider the implications of an entry subsidy equivalent to first $1 \%$ and then $5 \%$ of GDP. The results are reported in Table 7.

The direct effect of the entry subsidy is to increase entry. In Panel A, the measure of entrants increases from $73.6 \%$ to $75.3 \%$, and there is a slight increase in their R\&D intensity. The demand for skilled labor that additional entry induces raises the skilled wage by $3 \%$ (from 13.64 to 14.06 ).

TABle 7. Entry Subsidy

\begin{tabular}{ccccccccccccc}
\hline \hline \multicolumn{10}{c}{ PANEL A. 1\% OF GDP $\left(s_{e}=5 \%\right)$} \\
\hline \hline$x^{\text {entry }}$ & $x^{l}$ & $x^{h}$ & $m$ & $\Phi^{l}$ & $\Phi^{h}$ & $\hat{q}_{l, \min }$ & $\hat{q}_{h, \min }$ & $d r o p_{l}$ & $\frac{w^{s}}{w^{u}}$ & $\tau$ & $g$ & Wel \\
\hline 8.46 & 2.73 & 9.30 & 75.3 & 71.16 & 24.41 & 15.91 & 0.00 & 0.07 & 14.06 & 10.59 & 2.26 & 100.15 \\
\hline \hline \multicolumn{10}{c}{ PANEL B. 5\% OF GDP $\left(s_{e}=20 \%\right)$} \\
\hline \hline 8.47 & 2.49 & 8.35 & 80.0 & 71.01 & 24.01 & 24.10 & 0.00 & 0.11 & 15.75 & 10.55 & 2.32 & 100.63 \\
\hline \hline
\end{tabular}

Note: All numbers except wage ratio and welfare are in percentage terms.

As was the case with incumbent R\&D subsidies, the overall impact of the entry subsidy on growth is less than that induced by the change in the entry rate because, this time, the implied increase in the creative destruction rate and the higher skilled wages discourage innovation by incumbents. In consequence, Table 7 shows that low-type firms reduce their innovation rate from $2.80 \%$ to $2.73 \%$, and high-type firms reduce theirs from $9.58 \%$ to $9.30 \%$. With these two offsetting effects, the aggregate creative destruction rate remains essentially unchanged. Another interesting general equilibrium effect works through obsolescence. The higher skilled wage increases the threshold for exit, especially for low types (which increases from 0.139 to 0.159 ). This raises the obsolescence rate for low-type firms, and generates a beneficial selection effects, also contributing to growth. Therefore, the overall effect of the entry subsidy in Panel A is to increase the long-run growth rate of the economy from $2.24 \%$ to $2.26 \%$, and aggregate welfare by $0.15 \%$.

In Panel B, the overall pattern is similar, but the effects are somewhat larger. Growth now increases from $2.24 \%$ to $2.32 \%$, and welfare increases by $0.63 \%$. 
In summary, an entry subsidy has a positive effect on growth and welfare, but even with a subsidy amounting to $5 \%$ of GDP, this impact is small.

\subsection{Social Planner}

The results of the previous subsection might suggest that the equilibrium is close to optimal, and this is the reason why subsidies to incumbent $R \& D$ do not increase growth or welfare, and subsidies to entrants have a small effect. In this subsection, we will see that this is very far from the truth.

We characterize the allocation that a welfare-maximizing social planner would choose. Since we are not interested in monopoly distortions per se, we restrict the social planner to the same production and pricing decisions as the equilibrium, and only allow her to control the entry, exit and $\mathrm{R} \& \mathrm{D}$ margins of different firms. It is straightforward to see that the social planner will choose the same per product R\&D rate for all high- and low-type firms. Then, we can represent the problem of the planner as choosing $\left\{\hat{q}_{h, \text { min }}, \hat{q}_{l, \min }, m, x^{h}, x^{l}, x^{e n t r y}\right\}$ to maximize representative household welfare (26) subject to the skilled labor market clearing condition (19).

Table 8 summarizes the allocation implied by social planner's choices.

Table 8. Social Planner

\begin{tabular}{cccccccccccc}
\hline \hline$x^{\text {entry }}$ & $x^{l}$ & $x^{h}$ & $m$ & $\Phi^{l}$ & $\Phi^{h}$ & $\hat{q}_{l, \min }$ & $\hat{q}_{h, \min }$ & $d r o p_{l}$ & $\tau$ & $g$ & Wel \\
\hline 8.46 & 2.55 & 10.47 & 80.90 & 54.06 & 27.76 & 118.6 & 1.02 & 1.11 & 11.13 & 3.80 & 106.46 \\
\hline \hline
\end{tabular}

Several results are noteworthy. First, the social planner can improve growth and welfare greatly. Growth increases from $2.24 \%$ to $3.8 \%$ - a $70 \%$ increase in the growth rate. Welfare increases by $6.46 \%$. This result clearly establishes that the equilibrium was far from optimal. It was just that the three policy variations we considered were not the right ones for moving the economy towards a better allocation of resources.

Second, we can also see from Table 8 how the optimal allocation should look like. To start with, the obsolescence channel is now much stronger. Instead of $0.06 \%$ of low-type firms exiting this channel, we now have $1.11 \%$ doing so $\left(\hat{q}_{l \text {,min }}\right.$ increases from 13.9 to 118.6 , and the share of obsolescences in total exits increases from 1\% to 15\%). Also important is that the social planner increases $\mathrm{R} \& \mathrm{D}$ by high-type incumbents relative to the baseline (from $x^{h}=0.096$ to 0.104 ), while at the same time reducing $R \& D$ by low-types (from $x^{l}=0.028$ to 0.026 ). The result of all these changes is a very significant selection relative to the equilibrium: the ratio of high- to low-type firms increases from 0.34 to 0.51 ). This selection effect is at the root of the very large increase in growth and welfare. To be able to achieve this positive selection, the social planner keeps active a smaller fraction of product lines (though this is costly for welfare, the cost is more than outweighed by the beneficial selection). The social planner also increases the entry rate relative to equilibrium ( $m$ increases from 0.73 to 0.81 ).

We also computed the gains from the social planner's allocation relative to the equilibrium by shutting off the selection margin. The results reported in Table B1 in Appendix B show that, even 
though the social planner can again improve over the equilibrium, the extent of this improvement is more limited (less than half of that in Table 8), highlighting the critical role that the selection effect plays in our results.

\subsection{Optimal Policy}

The social planner's allocation discussed in the previous subsection relied on choosing the exit threshold and $R \& D$ rates of different types of firms. In practice, this type of detailed intervention may not be possible (for instance, firm type might be private information). A more reasonable set of policies might involve using: subsidies and/or taxes on (i) incumbent R\&D; (ii) costs of operation; (iii) entry. We analyze the optimal combination of these three policies in Panel A of Table 9.

The results are interesting. With these three instruments, each of which appeared fairly ineffective by itself, we can come quite close to the social planner's allocation. In particular, welfare can be increased by $4.56 \%$ and growth goes up to $3.12 \%$. This is achieved again by leveraging the selection effect, and involves a very large tax on the continued operation of all incumbents (a $246 \%$ tax). ${ }^{21}$ In addition, there is a modest subsidy to incumbent R\&D and to entry ( $17 \%$ and $6 \%$, respectively). The resulting allocation comes close to, but does not reach the social planner's allocation in the previous subsection. For example, the obsolescence rate is $0.77 \%$ instead of $1.11 \%$, and the ratio of high- to low-types is now $41 \%$ (instead of $51 \%$ under the social planner's allocation). Furthermore, with these instruments, it is not possible to simultaneously increase $R \& D$ by high-type firms and reduce it by the low-types, and for this reason, we see that the $R \& D$ rate by both types is now higher than in the baseline.

Table 9. Policy Analysis and Welfare

\begin{tabular}{|c|c|c|c|c|c|c|c|c|c|c|c|c|}
\hline \multicolumn{13}{|c|}{ Panel A. Optimal InCumbent and Entry Policies $\left(s_{i}=17 \%, s_{o}=-246 \%, s_{e}=6 \%\right)$} \\
\hline$x^{e n t r y}$ & $x^{l}$ & $x^{h}$ & $m$ & $\Phi^{l}$ & $\Phi^{h}$ & $\hat{q}_{l, \text { min }}$ & $\hat{q}_{h, \min }$ & drop & $\frac{w^{s}}{w^{u}}$ & $\tau$ & $g$ & Wel \\
\hline 8.46 & 3.04 & 10.20 & 75.4 & 62.17 & 25.53 & 96.39 & 56.01 & 0.77 & 9.02 & 10.88 & 3.12 & 104.56 \\
\hline \multicolumn{13}{|c|}{ Panel B. Optimal Incumbent Policies $\left(s_{i}=12 \%, s_{o}=-264 \%\right)$} \\
\hline 8.47 & 3.04 & 10.21 & 75.3 & 62.31 & 25.53 & 95.38 & 54.85 & 0.76 & 8.53 & 10.88 & 3.11 & 104.56 \\
\hline
\end{tabular}

Though subsidizing incumbent R\&D and taxing their operating costs (or subsidizing their exit) is in principle straightforward, subsidizing entry may be more difficult, because this corresponds, in our model, to the entry of innovative firms, and R\&D subsidies to non-existing firms may not be feasible. Therefore, arguably, relying just on incumbent policies (subsidies to incumbent R\&D and subsidies or taxes on operations) may be more reasonable. Panel B shows that just focusing on these two policies essentially generates the same benefits. When thus restricted, it would be optimal to increase the tax on operations further, to $264 \%$, and reduce incumbent subsidies to R\&D

\footnotetext{
${ }^{21}$ Recall that this is a tax on the fixed costs of operation, $w^{s} \phi$, not on all costs or revenues of firms. The $246 \%$ tax on the fixed costs of operation of incumbents is equivalent to an average tax of $26 \%$ on the revenues of incumbents.
} 
to $12 \%$ (so as not to discourage entry too much). These policies achieve almost the same growth increases and essentially the same welfare increase.

In summary, optimal policies can aggressively tax the operations of incumbents to encourage low-type firms to exit, thus exploiting the selection effect to increase the ratio of high-type firms to low-type firms. This can raise the growth rate of the economy to above $3.1 \%$ and increase welfare by more than $4.5 \%$. Entry subsidies or subsidies to incumbent R\&D do not achieve this objective, and this is the reason why we did not see major - or any-benefits from these policies. But they can be combined with very high taxes on the continued operation of incumbents to achieve major growth and welfare gains.

\section{Robustness}

In this section, we report the results of a few robustness exercises, which illustrate that the main results reported so far - in particular, the ability of the model to match the broad patterns in the micro data and the contrast between different types of industrial policies - are fairly robust. To save space, we discuss these results briefly, and the relevant tables are contained in Appendix B.

\subsection{Imposing $\gamma=0.5$}

As discussed in Section 4.4.2, though our estimate of $\gamma=0.64$ is in the middle of micro estimates of the elasticity of innovation to $\mathrm{R} \& \mathrm{D}$ expenditures, it is a little higher than more recent estimates based on instrumental-variable strategies exploiting changes in R\&D tax credits. In this subsection, we show that our main results are robust to imposing the central estimate of this more recent literature, $\gamma=0.5$.

For this purpose, we reestimated all of the parameters of our model, except that we imposed $\gamma=0.5$. The remaining parameter estimates and the match between model-generated and data moments are affected relatively little, and as a result, the implications of different industrial policies also remain broadly similar to our baseline. Analogous results to those in Tables $4-9$ are contained in Tables B2 and B3 Industrial policies (subsidies to incumbents) again reduce welfare, and subsidies to entrants again have a very small positive effect on growth and welfare. The social planner, instead, would be able to increase welfare by $2 \%$, and optimal policies just directed at incumbents ( $R \& D$ subsidies and taxes on continued operations) can increase welfare by $1.7 \%$.

\subsection{Imposing $\varrho=0$}

In our model, the parameter $\varrho$ regulates the share of productivity growth unrelated to R\&D activities. Although, as Table 3 shows, the implied estimate of this share in our model is in the ballpark of what we observe from the subsample of firms for which we can derive an estimate of it in the data ( $27 \%$ in the data as opposed to our estimates of $23 \%$ ), none of our 21 moments directly target the parameter $\varrho$. It is therefore informative to investigate whether the specific value for this 
parameter plays an important role in our results. With this purpose, we reestimated the model's remaining parameters imposing $\varrho=0$ (an extreme value but in line with what is implicitly imposed in other models of this sort). Tables B4 and B5 show that the implications of this restriction on our policy analysis are relatively minor. Subsidies to incumbents again reduce welfare and subsidies to entrants again have a very small positive effect. The social planner can now increase welfare by even a more striking amount (11\%), because $R \& D$ activities and selection become even more important. The combination of incumbent $\mathrm{R} \& \mathrm{D}$ subsidies and taxes on continued operations can now achieve quite a bit less than the social planner's allocation, but still significantly more than the equilibrium: growth increases to $3.3 \%$ and welfare can be increased by $5.9 \%$.

\subsection{Fixed Entrant Supply}

Our results so far show that the entry margin is very elastic-policies leave the R\&D rate of entrants, $x^{\text {entry }}$, largely unchanged and impact mainly $m$. One might be worried about whether this exaggerates how elastic the entry margin is. To see if this very elastic entry margin is partially responsible for our results, we reestimated all of the model parameters by imposing $m=1$, so that all variations in entry come from the intensive margin, $x^{\text {entry }}$ (which is less elastic because of the complex R\&D technology in (5)). With this modification, the fit of the model remains comparable to our baseline, and Tables B6 and B7 show that the results of the policy analysis are also broadly

comparable. One difference is that in this case, subsidies to incumbent R\&D have a small positive effect on welfare, rather than the negative effect we have seen in all the other cases so far. This reflects the fact that, with a less elastic entry margin, the cost of incumbent $\mathrm{R} \& \mathrm{D}$ in terms of reduced entry is less pronounced. The remaining results are very similar to those reported above. Subsidies to incumbent operations reduce welfare, and the social planner would be able to improve growth and welfare by leveraging the selection effect. In particular, the social planner can increase welfare by $2.6 \%$, and just using subsidies to incumbent R\&D and taxes on operations can increase welfare by $1.2 \%$.

\section{Conclusions}

In this paper we build a micro-founded model of firm innovation and growth. The model enables us an examination of the forces jointly driving innovation, productivity growth and reallocation. We estimate the parameters of the model using simulated method of moments on detailed US Census Bureau micro data on employment, output, R\&D and patenting. Our model fits the key moments from microdata reasonably well, and also performs well on non-targeted moments and is in line with the range of micro estimates in the literature.

We use the model to investigate the implications of several types of industrial policies on longrun growth and welfare. We find that industrial policies (subsidies to incumbent R\&D or to their operating costs) reduce growth and welfare, while entry subsidies have a positive but very small 
effect. These small effects are not because the equilibrium of our model is approximately optimal. On the contrary, a social planner limited to affecting only R\&D, entry and exit decisions can increase growth from $2.24 \%$ to $3.8 \%$, and increase welfare by $6.46 \%$. The social planner achieves this by strongly leveraging the selection effect. She forces low-type incumbents to exit at a very high rate, reduces their $\mathrm{R} \& \mathrm{D}$, and increases the $\mathrm{R} \& \mathrm{D}$ of high-type incumbents. Interestingly, relying on just subsidies to incumbent $\mathrm{R} \& \mathrm{D}$ and taxes on the continued operation of incumbents comes close to achieving this welfare gain (by introducing a very high tax on the continued operation of incumbents).

Our general equilibrium model which incorporates both reallocation and selection effects highlights the potential pitfalls of industrial policies supporting incumbents, particularly large incumbents. It also cautions against policies based on the prior that, because there is underinvestment in R\&D all R\&D-type activities should be subsidized. Entry does indeed play an important role in our estimated model, but it turns out to be much better to support entry by freeing resources from inefficient, low-type incumbents rather than subsidizing entry directly.

Several further topics of inquiry are left for future research. First, it would be interesting to extend our analysis to incorporate an endogenous selection between non-innovation and innovation, and also to incorporate reallocation of other resources (unskilled labor and capital). Second, our analysis has been confined to steady-state (balanced growth path) comparisons. It is likely that even our limited welfare gains from various types of industrial policy will be even more muted when transitional dynamics are taken into account (and it remains an open question whether the social planner can still significantly improve over the equilibrium allocation). Third, we have abstracted from costs of adjustment, which are important both for firms and workers, and may reduce the gains from reallocation. Fourth and related is a possible extension of this framework to model the joint dynamics of innovation, reallocation and unemployment, which can enrich the analysis of the effects of various policies, and also enable us to incorporate some of the potential unemployment benefits of supporting incumbent producers. Fifth, we have also abstracted from political constraints. It would be important to consider the political economy of different types of industrial policies, which have often been politically difficult to manage and prone to capture. Sixth, our model can also be used to study mergers between high- and low-type firms which might be able to make more efficient use of the existing knowledge stock of low-type firms in certain circumstances. Finally, supplementing our approach with more direct estimation of the costs and benefits of different types of policies targeted at $R \& D$ by incumbents is a major area for future research.

\section{References}

Acemoglu, Daron, Introduction to Modern Economic Growth, Princeton University Press (2008). Acs, Zoltan, and David Audretsch, "Innovation in Large and Small Firms: An Empirical Analysis", American Economic Review 78 (1988), 678-690. 
Acs, Zoltan, and David Audretsch, Innovation and Small Firms, MIT Press (1990).

Aghion, Philippe, and Peter Howitt, "A Model of Growth Through Creative Destruction", Econometrica 110 (1992), 323-351.

Aghion, Philippe, Mathias Dewatripont, Luosha Du, Ann Harrison, and Patrick Legros, "Industrial Policy and Competition", NBER Working Paper 18048 (2012).

Akcigit, Ufuk, "Firm Size, Innovation Dynamics and Growth", University of Pennsylvania Working Paper (2010).

Akcigit, Ufuk, Douglas Hanley, and Nicolas Serrano-Velarde, "Back to Basics: Basic Research Spillovers, Innovation Policy and Growth", University of Pennsylvania Working Paper (2012).

Akcigit, Ufuk, and William Kerr, "Growth through Heterogeneous Innovations", NBER Working Paper 16443 (2010).

Balasubramanian, Natarajan, and Jagadeesh Sivadasan, "What Happens When Firms Patent? New Evidence from US Economic Census Data", Review of Economics and Statistics 93 (2011), 126-146.

Bartelsman, Eric, John Haltiwanger, and Stefano Scarpetta, "Cross-Country Differences in Productivity: The Role of Allocation and Selection", NBER Working Paper 15490 (2009).

Bloom, Nicholas, Rachel Griffith, and John Van Reenen, "Do R\&D Tax Credits Work?", Journal of Public Economics 85 (2002), 1-31.

Blundell, Richard, Rachael Griffith, and Frank Windmeijer, "Individual Effects and Dynamics in Count Data Models", Journal of Econometrics 108 (2002), 113-131.

Cohen, Wesley, and Steven Klepper, "A Reprise of Size and R\&D", Economic Journal 106 (1996a), 925-951.

Cohen, Wesley, and Steven Klepper, "Firm Size and the Nature of Innovation within Industries: The Case of Process and Product R\&D", Review of Economics and Statistics 78 (1996b), 232-243.

Corsino, Marco, Giuseppe Espa, and Rocco Micciolo, "R\&D, Firm Size and Incremental Product Innovation", Economics of Innovation and New Technology 20 (2011), 423-443.

Criscuolo, Chiara, Ralf Martin, Henry Overman, and John Van Reenen, "The Causal Effects of Industrial Policy", CEP Working Paper 1113 (2012).

Ericson, Richard, and Ariel Pakes, "Markov-Perfect Industry Dynamics: A Framework for Empirical Work", Review of Economic Studies 62 (1995), 53-82.

European Commission, State Aid Scorecard, Brussels: European Commission, http://ec.europa.eu/competition/state_aid/studies_reports/studies_reports.html (2011).

Foster, Lucia, and Cheryl Grim, "Characteristics of the Top R\&D Performing Firms in the U.S.: Evidence from the Survey of Industrial R\&D”, CES Working Paper 10-33 (2010).

Foster, Lucia, John Haltiwanger, and C.J. Krizan, "Aggregate Productivity Growth: Lessons from Microeconomic Evidence", in New Developments in Productivity Analysis, University of Chicago Press (2000).

Foster, Lucia, John Haltiwanger, and C.J. Krizan, "Market Selection, Reallocation and Re- 
structuring in the U.S. Retail: Trade Sector in the 1990s", Review of Economics and Statistics 88 (2006), 748-758.

Foster, Lucia, John Haltiwanger, and Chad Syverson, "Reallocation, Firm Turnover and Efficiency: Selection on Productivity or Profitability?", American Economic Review 98 (2008), 394-425.

Goolsbee, Austan, "Does Government R\&D Policy Mainly Benefit Scientists and Engineers?" NBER Working Paper 6532 (1998).

Griliches, Zvi, "Patent Statistics as Economic Indicators: A Survey", Journal of Economic Literature 28 (1990), 1661-1707.

Grossman, Gene M. and Elhanan Helpman, Innovation and Growth in the Global Economy, MIT Press (1991).

Guner, Nezih, Gustavo Ventura, and Yi Xu, "Macroeconomic Implications of Size-Dependent Policies", Review of Economic Dynamics 11 (2008), 721-744.

Hall, Bronwyn, "R\&D Tax Policy During the 1980s: Success or Failure?", Tax Policy and the Economy 7 (1992), 1-36.

Hall, Bronwyn, Adam Jaffe, and Manuel Trajtenberg, "The NBER Patent Citation Data File: Lessons, Insights and Methodological Tools", NBER Working Paper 8498 (2001).

Hall, Bronwyn, and John Van Reenen, "How Effective are Fiscal Incentives for R\&D? A Review of the Evidence", Research Policy 29 (2000), 449-469.

Hall, Bronwyn, and Rosemarie Zeidonis, "The Patent Paradox Revisited: An Empirical Study of Patenting in the U.S. Semiconductor Industry, 1979-1995", RAND Journal of Economics 32 (2001), 101-128.

Haltiwanger, John, Ron Jarmin, and Javier Miranda, "Who Creates Jobs? Small vs. Large vs. Young", Review of Economics and Statistics 95 (2013), forthcoming.

Hsieh, Chang-Tai, and Peter Klenow, "Misallocation and Manufacturing TFP in China and India", Quarterly Journal of Economics 124 (2009), 1403-1448.

Hopenhayn, Hugo, "Entry, Exit, and Firm Dynamics in Long Run Equilibrium", Econometrica 60 (1992), 1127-1150.

Hopenhayn, Hugo, "On the Measure of Distortions", UCLA Working Paper (2012).

Hopenhayn, Hugo, and Richard Rogerson, "Job Turnover and Policy Evaluation: A General Equilibrium Analysis", Journal of Political Economy 101 (1993), 915-938.

Jones, Charles, "R\&D-Based Models of Economic Growth", Journal of Political Economy 103 (1995), 759-784.

Jones, Charles, "Misallocation, Economic Growth, and Input-Output Economics", NBER Working Paper 16742 (2011).

Jovanovic, Boyan, "Selection and the Evolution of Industry", Econometrica 50 (1982), 649-670.

Kerr, William, and Shihe Fu, "The Survey of Industrial R\&D-Patent Database Link Project", Journal of Technology Transfer 33 (2008), 173-186. 
Klette, Tor Jakob, and Samuel Kortum, "Innovating Firms and Aggregate Innovation", Journal of Political Economy 112 (2004), 986-1018.

Lee, Chang-Yang, and Taeyoon Sung, "Schumpeter's Legacy: A New Perspective on the Relationship between Firm Size and R\&D", Research Policy 34 (2005), 914-931.

Lentz, Rasmus, and Dale Mortensen, "An Empirical Model of Growth through Product Innovation", Econometrica 76 (2008), 1317-1373.

Lerner, Josh, Boulevard of Broken Dreams: Why Public Efforts to Boost Entrepreneurship and Venture Capital Have Failed and What to Do About It, Princeton University Press (2012).

Kogan, Leonid, Dimitris Papanikolaou, Amit Seru, and Noah Stoffman, "Technological Innovation, Resource Allocation, and Growth", NBER Working Paper 17769 (2012).

McFadden, Daniel, "A Method of Simulated Moments for Estimation of Discrete Response Models Without Numerical Integration", Econometrica 57 (1989), 995-1026.

Owen, Geoffrey, From Empire to Europe, HaperCollins (2000).

Pakes, Ariel, and David Pollard, "Simulation and the Asymptotics of Optimization Estimators", Econometrica 57 (1989), 1027-1057.

Peters, Michael, "Heterogeneous Mark-Ups and Endogenous Misallocation", Yale Working Paper (2012).

Rattner, Steven, Overhaul: An Insider's Account of the Obama Administration's Emergency Rescue of the Auto Industry, Houghton Mifflin Harcourt Trade (2010).

Restuccia, Diego, and Richard Rogerson, "Policy Distortions and Aggregate Productivity with Heterogeneous Plants", Review of Economic Dynamics 11 (2008), 707-720.

Romer, Paul M., "Endogenous Technological Change", Journal of Political Economy 98 (1990), S71-S102.

Romer, Paul M. "Should the Government Subsidize Supply or Demand in the Market for Scientists and Engineers?." In Innovation Policy and the Economy, Volume 1. MIT Press, (2001) 221-252.

Syverson, Chad, "What Determines Productivity", Journal of Economic Literature 49 (2011), 326-365.

Tether, Bruce, "Small and Large Firms: Sources of Unequal Innovations", Research Policy 27 (1998), 725-745.

Wilson, Daniel, "Beggar thy Neighbor? The In-State, Out-of-State and Aggregate Effects of R\&D Tax Credits", Review of Economics and Statistics 91 (2009), 431-436.

\section{Appendix A}

Proof of Lemma 1. Consider the low-type firms and conjecture $\tilde{V}_{l}(\hat{\mathcal{Q}})=\sum_{\hat{q} \in \hat{\mathcal{Q}}} \Upsilon^{l}(\hat{q})$ :

$$
r \sum_{\hat{q} \in \hat{\mathcal{Q}}} \Upsilon^{l}(\hat{q})=\sum_{\hat{q} \in \hat{\mathcal{Q}}} \max \left\{0, \max _{x}\left[\begin{array}{c}
\tilde{\pi}\left(\hat{q}_{j}\right)-\tilde{w}^{s} \phi^{s}-\tilde{w}^{s} G\left(x, \theta^{L}\right)+\frac{\partial \Upsilon^{l}(\hat{q})}{\partial \hat{q}} \frac{\partial \hat{q}}{\partial w^{u}} \frac{\partial w^{u}}{\partial t} \\
+x \mathbb{E} \Upsilon^{l}(\hat{q}(1+\lambda))+\hat{\varrho} \mathbb{E} \Upsilon^{l}(\hat{q})-(\tau+\varphi) \Upsilon^{l}(\hat{q})
\end{array}\right]\right\}
$$


This expression reduces to

$$
r \Upsilon^{l}(\hat{q})=\max \left\{0,\left\{\begin{array}{c}
\tilde{\pi}(\hat{q})-\tilde{w}^{s} \phi^{s}+\frac{\partial \Upsilon^{l}(\hat{q})}{\partial \hat{q}} \frac{\partial \hat{q}}{\partial w^{u}} \frac{\partial w^{u}}{\partial t}-(\tau+\varphi) \Upsilon^{l}(\hat{q}) \\
+\hat{\varrho} \mathbb{E} \Upsilon^{l}(\hat{q})+\max _{x}\left[x \mathbb{E} \Upsilon^{l}(\hat{q}(1+\lambda))-\tilde{w}^{s} G\left(x, \theta^{L}\right)\right]
\end{array}\right\}\right\}
$$

where we also use the fact that a firm can choose not to operate an individual product line.

Next consider the high-type firms and conjecture $\tilde{V}_{h}(\hat{\mathcal{Q}})=\sum_{\hat{q} \in \hat{\mathcal{Q}}} \Upsilon^{h}(\hat{q})$ :

$$
r \sum_{\hat{q} \in \hat{\mathcal{Q}}} \Upsilon^{h}(\hat{q})=\sum_{\hat{q} \in \hat{\mathcal{Q}}} \max \left\{0, \max _{x}\left[\begin{array}{c}
\tilde{\pi}(\hat{q})-\tilde{w}^{s} \phi^{s}-\tilde{w}^{s} G\left(x, \theta^{H}\right)+\frac{\partial \Upsilon^{h}(\hat{q})}{\partial \hat{q}} \frac{\partial \hat{q}}{\partial w^{u}} \frac{\partial w^{u}}{\partial t} \\
+x \mathbb{E} \Upsilon^{h}(\hat{q}(1+\lambda))+\hat{\varrho} \mathbb{E} \Upsilon^{h}(\hat{q}) \\
-(\tau+\varphi) \Upsilon^{h}(\hat{q})+\nu\left[\mathbb{I}_{\hat{q}>\hat{q}_{l, \min }} \cdot \Upsilon^{l}(\hat{q})-\Upsilon^{h}(\hat{q})\right]
\end{array}\right]\right\}
$$

which, with similar steps, reduces to

$$
r \Upsilon^{h}(\hat{q})=\max \left\{0, \max _{x}\left[\begin{array}{c}
\tilde{\pi}(\hat{q})-\tilde{w}^{s} \phi^{s}-\tilde{w}^{s} G\left(x, \theta^{H}\right)+\frac{\partial \Upsilon(\hat{q})}{\partial \hat{q}} \frac{\partial \hat{q}}{\partial w^{u}} \frac{\partial w^{u}}{\partial t}+ \\
x \mathbb{E} \Upsilon(\hat{q}(1+\lambda))+\hat{\varrho} \mathbb{E} \Upsilon^{h}(\hat{q}) \\
-(\tau+\varphi) \Upsilon(\hat{q})+\nu\left[\mathbb{I}_{\hat{q}>\hat{q}_{l, \min }} \cdot \Upsilon^{l}(\hat{q})-\Upsilon^{h}(\hat{q})\right]
\end{array}\right]\right\}
$$

Monotonicity follows from the fact that the per-period return function is increasing in $\hat{q}$.

Proof of Proposition 1. First note that $\tilde{\pi}(q)=\left[\frac{\varepsilon-1}{\varepsilon}\right]^{\varepsilon} \frac{1}{\varepsilon-1} \hat{q}^{\varepsilon-1}=\Pi \hat{q}^{\varepsilon-1}$. Then, defining $\Psi \equiv r+\tau+\varphi$, equation (14) can be written as the following linear differential equation

$$
\Psi \Upsilon^{l}(\hat{q})+g \hat{q} \frac{\partial \Upsilon^{l}(\hat{q})}{\partial \hat{q}}=\Pi \hat{q}^{\varepsilon-1}+\Omega^{l}-\tilde{w}^{s} \phi \text { if } \hat{q}>\hat{q}_{l, \min }
$$

or

$$
\xi_{1} \hat{q}^{-1} \Upsilon^{l}(\hat{q})+\frac{\partial \Upsilon^{l}(\hat{q})}{\partial \hat{q}}=\xi_{2} \hat{q}^{\varepsilon-2}-\xi_{3} \hat{q}^{-1}
$$

where $\xi_{1} \equiv \frac{\Psi}{g}, \xi_{2} \equiv \frac{\Pi}{g}$ and $\xi_{3} \equiv \frac{\tilde{w}^{s} \phi-\Omega^{l}}{g}$. Then the solution to (28) can be written as

$$
\Upsilon^{l}(\hat{q})=\hat{q}^{-\xi_{1}}\left(\int\left[\xi_{2} \hat{q}^{\xi_{1}+\varepsilon-2}-\xi_{3} \hat{q}^{\xi_{1}-1}\right] d x+D\right)=\frac{\xi_{2} \hat{q}^{\varepsilon-1}}{\xi_{1}+\varepsilon-1}-\frac{\xi_{3}}{\xi_{1}}+D \hat{q}^{-\xi_{1}}
$$

where

$$
f(\hat{q}) \equiv \xi_{1} \hat{q}^{-1}, y(\hat{q}) \equiv \Upsilon^{l}(\hat{q}) \text { and } g(\hat{q}) \equiv \xi_{2} \hat{q}^{\varepsilon-2}-\xi_{3} \hat{q}^{-1} .
$$

Imposing the boundary condition $\Upsilon^{l}\left(\hat{q}_{l, \text { min }}\right)=0$, we can solve out for the constant of integration $D$, obtaining

$$
\begin{aligned}
\Upsilon^{l}(\hat{q}) & =\frac{\xi_{2} \hat{q}^{\varepsilon-1}}{\xi_{1}+\varepsilon-1}-\frac{\xi_{3}}{\xi_{1}}+\left[\frac{\xi_{3} \hat{q}_{l, \text { min }}^{\xi_{1}}}{\xi_{1}}-\frac{\xi_{2} \hat{q}_{l, \text { min }}^{\xi_{1}+\varepsilon-1}}{\xi_{1}+\varepsilon-1}\right] \hat{q}^{-\xi_{1}} \\
& =\frac{\Pi \hat{q}^{\varepsilon-1}}{\Psi+(\varepsilon-1) g}\left[1-\left(\frac{\hat{q}_{l, \text { min }}}{\hat{q}}\right)^{\frac{\Psi}{g}+\varepsilon-1}\right]+\frac{\Omega^{l}-\tilde{w}^{s} \phi}{\Psi}\left[1-\left(\frac{\hat{q}_{l, \text { min }}}{\hat{q}}\right)^{\frac{\Psi}{g}}\right] .
\end{aligned}
$$

The derivation of the value for a high-type product line is similar and is provided in the online appendix. 
Proof of Proposition 2. Let $Q_{t} \equiv\left[\int_{\mathcal{N}_{t}} q_{j t}^{\varepsilon-1} d j\right]^{\frac{1}{\varepsilon-1}}$ and

$$
\tilde{Q}_{t} \equiv Q_{t}^{\varepsilon-1}=\int_{\mathcal{N}_{t}} q_{j t}^{\varepsilon-1} d j=\int_{\mathcal{N}_{t}^{h}} q_{j t}^{\varepsilon-1} d j+\int_{\mathcal{N}_{t}^{l}} q_{j t}^{\varepsilon-1} d j=\tilde{Q}_{t}^{h}+\tilde{Q}_{t}^{l},
$$

where $\tilde{Q}_{t}^{k} \equiv \int_{\mathcal{N}_{t}^{k}} q_{j t}^{\varepsilon-1} d j$. Clearly,

$$
\frac{\partial \tilde{Q}_{t} / \tilde{Q}_{t}}{\partial t}=\frac{\tilde{Q}^{h}}{\tilde{Q}_{t}^{h}+\tilde{Q}_{t}^{l}} g_{h}+\frac{\tilde{Q}^{l}}{\tilde{Q}_{t}^{h}+\tilde{Q}_{t}^{l}} g_{l}
$$

where $g_{k}=\frac{\partial \tilde{Q}^{k}}{\partial t} \frac{1}{\tilde{Q}^{k}}$ for $k \in\{h, l\}$.

Now to find $g_{h}$, let us write

$$
\tilde{Q}_{t+\Delta t}^{h}=\left\{\begin{array}{c}
\left(x^{h}+\alpha X^{\text {entry }}\right) \Delta t\left((1+\lambda) q_{j t}\right)^{\varepsilon-1} \\
\int_{\mathcal{N}_{t}^{h}}\left\{\begin{array}{c} 
\\
+(1-\Delta t-\nu \Delta t-\varphi \Delta t)\left[1-F_{h}\left((1+g \Delta t) \hat{q}_{h, \text { min }}\right)\right] q_{j t}^{\varepsilon-1}
\end{array}\right\} d j \\
+\int_{\mathcal{N}_{t}^{l}}\left(x^{h}+\alpha X^{\text {entry }}\right) \Delta t\left((1+\lambda) q_{j t}\right)^{\varepsilon-1} d j \\
+\int_{\mathcal{N}_{t}^{n p}}^{n}\left(x^{h}+\alpha X^{\text {entry }}+\varrho \Phi^{h}\right) \Delta t \mathbb{E} q_{t+\Delta t}^{\varepsilon-1} d j
\end{array}\right\}
$$

Hence

$$
\begin{aligned}
\lim _{\Delta t \rightarrow 0} \frac{\tilde{Q}_{t+\Delta t}^{h}-\tilde{Q}_{t}^{h}}{\tilde{Q}_{t}^{h} \Delta t}=\left\{\begin{array}{c}
\left(x^{h}+\alpha X^{\text {entry }}\right)(1+\lambda)^{\varepsilon-1} \\
-g \hat{q}_{h, \text { min }} f_{h}\left(\hat{q}_{h, \text { min }}\right)-[\tau+\nu+\varphi] \\
+\left(x^{h}+\alpha X^{\text {entry }}\right)(1+\lambda)^{\varepsilon-1} \tilde{\tilde{Q}}_{t}^{l} \\
+\left(x^{h}+\alpha X^{\text {entry }}+\varrho \Phi^{h}\right) \frac{\Phi^{n p} \mathbb{E} q_{t}^{\varepsilon-1}}{\tilde{Q}_{t}^{h}}
\end{array}\right\} \\
g_{h}=\left\{\begin{array}{c}
\left(x^{h}+\alpha X^{\text {entry }}\right)\left[(1+\lambda)^{\varepsilon-1}\left(1+\frac{\tilde{Q}_{t}^{l}}{\tilde{Q}_{t}^{h}}\right)+\frac{\Phi^{n p} \mathbb{E}_{t}^{\varepsilon-1}}{\tilde{Q}_{t}^{h}}\right] \\
-g \hat{q}_{h, \min } f_{h}\left(\hat{q}_{h, \text { min }}\right)+\varrho \Phi^{h} \frac{\Phi^{n p} \mathbb{E}_{t}^{\varepsilon-1}}{\tilde{Q}_{t}^{h}}-[\tau+\nu+\varphi]
\end{array}\right\}
\end{aligned}
$$

Similarly for $g_{l}$, we have

$$
\tilde{Q}_{t+\Delta t}^{l}=\left\{\begin{array}{c}
\left(x^{l}+(1-\alpha) X^{\text {entry }}\right) \Delta t(1+\lambda)^{\varepsilon-1} \tilde{Q}_{t}^{l} \\
-F_{l}\left((1+g \Delta t) \hat{q}_{l, \text { min }}\right) \tilde{Q}_{t}^{l}+\tilde{Q}_{t}^{l}-[\tau+\varphi] \Delta t \tilde{Q}_{t}^{l} \\
+\left[\left(x^{l}+(1-\alpha) X^{\text {entry }}\right)(1+\lambda)^{\varepsilon-1}+\nu\left[1-F_{h}\left(\hat{q}_{l, \text { min }}\right)\right]\right] \Delta t \tilde{Q}_{t}^{l} \\
+\left(x^{l}+(1-\alpha) X^{\text {entry }}+\varrho \Phi^{l}\right) \Delta t \Phi^{n p} \mathbb{E} q_{t+\Delta t}^{\varepsilon-1}
\end{array}\right\},
$$

which with similar steps yields

$$
g_{l}=\left\{\begin{array}{c}
\left(x^{l}+(1-\alpha) X^{\text {entry }}\right)\left[(1+\lambda)^{\varepsilon-1}\left(1+\frac{\tilde{Q}_{t}^{h}}{\tilde{Q}_{t}^{l}}\right)+\frac{\Phi^{n p} \mathbb{E} q_{t}^{\varepsilon-1}}{\tilde{Q}_{t}^{l}}\right] \\
+\nu\left[1-F_{h}\left(\hat{q}_{l, \text { min }}\right)\right] \frac{\tilde{Q}_{t}^{h}}{\tilde{Q}_{t}^{l}}+\varrho \Phi^{l} \frac{\Phi^{n p} \mathbb{E} q_{t}^{\varepsilon-1}}{\tilde{Q}_{t}^{l}}-g \hat{q}_{l, \text { min }} f_{l}\left(\hat{q}_{l, \text { min }}\right)-[\tau+\varphi]
\end{array}\right\} .
$$

In the stationary equilibrium, $\tilde{Q}_{t}^{h} / \tilde{Q}_{t}^{l}$ is constant, and hence $g_{h}=g_{l}$, which implies

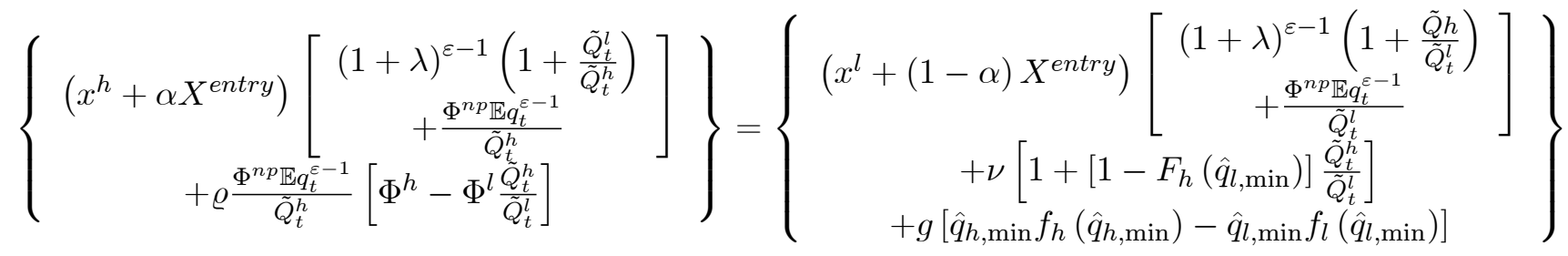


Finally, defining $\frac{\tilde{Q}_{t}^{h}}{\tilde{Q}_{t}^{l}} \equiv \Gamma, \frac{\Phi^{n p} \mathbb{E} q_{t}^{\varepsilon-1}}{\tilde{Q}_{t}^{h}} \equiv \varkappa_{h}$ and $\frac{\Phi^{n p} \mathbb{E} q_{t}^{\varepsilon-1}}{\tilde{Q}_{t}^{l}} \equiv \varkappa_{l}$, we obtain

$$
\left\{\begin{array}{c}
\left(x^{h}+\alpha X^{e n t r y}\right)\left[(1+\lambda)^{\varepsilon-1}\left(1+\frac{1}{\Gamma}\right)+\varkappa_{h}\right] \\
+\varrho \varkappa_{h}\left[\Phi^{h}-\Phi^{l} \Gamma\right]
\end{array}\right\}=\left\{\begin{array}{c}
\left(x^{l}+(1-\alpha) X^{e n t r y}\right)\left[(1+\lambda)^{\varepsilon-1}(1+\Gamma)+\varkappa_{l}\right] \\
+\nu\left[1+\left[1-F_{h}\left(\hat{q}_{l, \min }\right)\right] \Gamma\right] \\
+g\left[\hat{q}_{h, \min } f_{h}\left(\hat{q}_{h, \min }\right)-\hat{q}_{l, \text { min }} f_{l}\left(\hat{q}_{l, \min }\right)\right]
\end{array}\right\}
$$

Imposing $g=\frac{g_{h}}{\varepsilon-1}=\frac{g_{l}}{\varepsilon-1}$ and using (30) completes the proof.

Proof of Lemma 3. In a stationary equilibrium inflows and outflows into different parts of the distributions have to be equal. Considering a time interval of $\Delta t$, this implies $\Phi^{h} F_{h}(\hat{q}, t)=$ $\Phi^{h} F_{h}(\hat{q}, t+\Delta t)$ for

$$
\begin{gathered}
\Phi^{h} F_{h}(\hat{q})=\left\{\begin{array}{c}
\Phi^{h}(1-(\tau+\varphi+\nu) \Delta t)\left[F_{h}(\hat{q}(1+g \Delta t))-F_{h}\left(\hat{q}_{h, \min }(1+g \Delta t)\right)\right] \\
+\left(\Phi^{h} x^{h}+\alpha X^{e n t r y}\right) \Delta t\left[\begin{array}{c}
\Phi^{h} F_{h}\left(\hat{q} \frac{1+g \Delta t}{1+\lambda}\right)+\Phi^{l} F_{l}\left(\hat{q} \frac{1+g \Delta t}{1+\lambda}\right) \\
+\left(1-\Phi^{h}-\Phi^{l}\right) F(\hat{q})
\end{array}\right], \hat{q}_{h, \text { crit }}<\hat{q}
\end{array}\right. \\
\Phi^{h} F_{h}(\hat{q})=\Phi^{h}(1-(\tau+\varphi+\nu) \Delta t)\left[F_{h}(\hat{q}(1+g \Delta t))-F_{h}\left(\hat{q}_{h, \min }(1+g \Delta t)\right)\right], \begin{array}{c}
\hat{q}_{h, \text { min }}(1+g \Delta t) \\
<\hat{q} \leq \hat{q}_{h, \text { crit }}
\end{array}
\end{gathered}
$$

where $\hat{q}_{s, \text { crit }} \equiv \hat{q}_{s, \min }(1+\lambda), s \in\{l, h\}$. With a similar reasoning, we also have

$$
\begin{gathered}
\Phi^{l} F_{l}(\hat{q})=\left\{\begin{array}{c}
\Phi^{l}(1-(\tau+\varphi) \Delta t)\left[F_{l}(\hat{q}(1+g \Delta t))-F_{l}\left(\hat{q}_{l, \min }(1+g \Delta t)\right)\right] \\
\left.+\left(\Phi^{l} x^{l}+(1-\alpha) X^{e n t r y}\right) \Delta t\left[\begin{array}{c}
\Phi^{h} F_{h}\left(\hat{q} \frac{1+g \Delta t}{1+\lambda}\right)+\Phi^{l} F_{l}\left(\hat{q} \frac{1+g \Delta t}{1+\lambda}\right) \\
+\left(1-\Phi^{h}-\Phi^{l}\right) F(\hat{q})
\end{array}\right]\right\}, \hat{q}_{l, c r i t}<\hat{q} \\
+\nu \Delta t \Phi^{h}\left[F_{h}(\hat{q}(1+g \Delta t))-F_{h}\left(\hat{q}_{l, \min }(1+g \Delta t)\right]\right.
\end{array}\right\} \\
\Phi^{l} F_{l}(\hat{q})=\left\{\begin{array}{c}
\Phi^{l}(1-(\tau+\varphi) \Delta t)\left[F_{l}(\hat{q}(1+g \Delta t))-F_{l}\left(\hat{q}_{l, \min }(1+g \Delta t)\right)\right] \\
+\nu \Delta t \Phi^{h}\left[F_{h}(\hat{q}(1+g \Delta t))-F_{h}\left(\hat{q}_{l, \min }(1+g \Delta t)\right)\right]
\end{array}\right\}, \begin{array}{c}
\hat{q}_{l, \text { min }}(1+g \Delta t) \\
<\hat{q} \leq \hat{q}_{l, c r i t}
\end{array}
\end{gathered}
$$

Next, subtract $\Phi^{s} F_{s}(\hat{q}(1+g \Delta t))$ from both sides, multiply both sides by -1 , divide again both sides by $\Delta t$, and take the limit as $\Delta t \rightarrow 0$, so that

$$
\lim _{\Delta t \rightarrow 0} \frac{F_{s}(\hat{q}(1+g \Delta t))-F_{s}(\hat{q})-F_{s}\left(\hat{q}_{s, \min }(1+g \Delta t)\right)}{\Delta t}=g \hat{q} f_{s}(\hat{q})-g \hat{q}_{s, \min } f_{s}\left(\hat{q}_{s, \min }\right) .
$$

Using this last expression delivers (23) and (24). 


\title{
Online Appendix B for "Innovation, Reallocation and Growth"
}

\author{
Daron Acemoglu Ufuk Akcigit Nicholas Bloom William Kerr \\ MIT \\ UPenn \\ Stanford \\ Harvard
}

April 12, 2013

In this Appendix, we provide additional results and the proofs of all the results stated in the text, and depict the details of some of the robustness exercises mentioned in the text.

\section{B-1 Proofs and Derivations}

Detailed Proof of Proposition 1. Let the profit be expressed as

$$
\begin{aligned}
\tilde{\pi}(q) & =\left[\frac{\varepsilon-1}{\varepsilon}\right]^{\varepsilon} \frac{1}{\varepsilon-1} \hat{q}^{\varepsilon-1} \\
& =\Pi \hat{q}^{\varepsilon-1}
\end{aligned}
$$

Then equation (14) can be written as

$$
\Psi \Upsilon^{l}(\hat{q})+g \hat{q} \frac{\partial \Upsilon^{l}(\hat{q})}{\partial \hat{q}}=\Pi \hat{q}^{\varepsilon-1}+\Omega^{l}-\tilde{w}^{s} \phi \text { if } \hat{q}>\hat{q}_{l, \min }
$$

or

$$
\xi_{1} \hat{q}^{-1} \Upsilon^{l}(\hat{q})+\frac{\partial \Upsilon^{l}(\hat{q})}{\partial \hat{q}}=\xi_{2} \hat{q}^{\varepsilon-2}-\xi_{3} \hat{q}^{-1}
$$

where

$$
\xi_{1} \equiv \frac{\Psi}{g}, \xi_{2} \equiv \frac{\Pi}{g} \text { and } \xi_{3} \equiv \frac{\tilde{w}^{s} \phi-\Omega^{l}}{g}
$$

and $\Psi=r+\tau+\varphi$. Let us drop the indices $(j, f)$ for notational convenience. Recall that for a differential equation of the form

$$
f(x) y(x)+y^{\prime}(x)=g(x),
$$

the general solution is

$$
y(x)=e^{-F(x)}\left(\int e^{F(x)} g(x) d x+D\right)
$$

where $F(x)=\int f(x) d x$ and $D$ is the constant of integration. We first define the following equalities

$$
f(\hat{q}) \equiv \xi_{1} \hat{q}^{-1}, y(\hat{q}) \equiv \Upsilon^{l}(\hat{q}) \text { and } g(\hat{q}) \equiv \xi_{2} \hat{q}^{\varepsilon-2}-\xi_{3} \hat{q}^{-1} .
$$

Then (28) - (B-2) imply $F(\hat{q})=\ln \hat{q}^{\xi_{1}}$ and

$$
\Upsilon^{l}(\hat{q})=\hat{q}^{-\xi_{1}}\left(\int\left[\xi_{2} \hat{q}^{\xi_{1}+\varepsilon-2}-\xi_{3} \hat{q}^{\xi_{1}-1}\right] d x+D\right)=\frac{\xi_{2} \hat{q}^{\varepsilon-1}}{\xi_{1}+\varepsilon-1}-\frac{\xi_{3}}{\xi_{1}}+D \hat{q}^{-\xi_{1}} .
$$


Imposing the boundary condition $\Upsilon^{l}\left(\hat{q}_{l, \min }\right)=0$

$$
D=\frac{\xi_{3} \hat{q}_{l, \text { min }}^{\xi_{1}}}{\xi_{1}}-\frac{\xi_{2} \hat{q}_{l, \text { min }}^{\xi_{1}+\varepsilon-1}}{\xi_{1}+\varepsilon-1}
$$

Therefore substituting back the constant term and the subindices we get

$$
\begin{aligned}
\Upsilon^{l}(\hat{q}) & =\frac{\xi_{2} \hat{q}^{\varepsilon-1}}{\xi_{1}+\varepsilon-1}-\frac{\xi_{3}}{\xi_{1}}+\left[\frac{\xi_{3} \hat{q}_{l, \text { min }}^{\xi_{1}}}{\xi_{1}}-\frac{\xi_{2} \hat{q}_{l, \text { min }}^{\xi_{1}+\varepsilon-1}}{\xi_{1}+\varepsilon-1}\right] \hat{q}^{-\xi_{1}} \\
& =\frac{\Pi \hat{q}^{\varepsilon-1}}{\Psi+(\varepsilon-1) g}\left[1-\left(\frac{\hat{q}_{l, \text { min }}}{\hat{q}}\right)^{\frac{\Psi}{g}+\varepsilon-1}\right]+\frac{\Omega^{l}-\tilde{w}^{s} \phi}{\Psi}\left[1-\left(\frac{\hat{q}_{l, \text { min }}}{\hat{q}}\right)^{\frac{\Psi}{g}}\right]
\end{aligned}
$$

where $\Psi \equiv r+\tau+\varphi$.

Now we turn to the value of high-type product line. We will focus only on the derivation of the differential equation. The rest follows the previous results. Let us rewrite the expression in (B-3) as

$$
\Upsilon^{l}(\hat{q})=\xi_{4} \hat{q}^{\varepsilon-1}+\xi_{5} \hat{q}^{-\frac{\Psi}{g}}-\xi_{6}
$$

where

$$
\xi_{4} \equiv \frac{\Pi}{\Psi+(\varepsilon-1) g}, \xi_{5}=\frac{\left(\tilde{w}^{s} \phi-\Omega^{l}\right) \hat{q}_{l, \min }^{\frac{\Psi}{g}}}{\Psi}-\frac{\Pi \hat{q}_{l, \min }^{\frac{\Psi}{g}+\varepsilon-1}}{\Psi+g(\varepsilon-1)}, \text { and } \xi_{6}=\frac{\tilde{w}^{s} \phi-\Omega^{l}}{\Psi}
$$

Recall the value of a product line of a high-type firm

$$
\begin{aligned}
& (\Psi+\nu) \Upsilon^{h}(\hat{q})+\frac{\partial \Upsilon^{h}(\hat{q})}{\partial \hat{q}} g \hat{q}=\Pi \hat{q}^{\varepsilon-1}+\Omega^{h}-\tilde{w}^{s} \phi+\nu\left[\xi_{4} \hat{q}^{\varepsilon-1}+\xi_{5} \hat{q}^{-\frac{\Psi}{g}}-\xi_{6}\right] \text { for } \hat{q} \geq \hat{q}_{l, \min } \\
& (\Psi+\nu) \Upsilon^{h}(\hat{q})+\frac{\partial \Upsilon^{h}(\hat{q})}{\partial \hat{q}} g \hat{q}=\Pi \hat{q}^{\varepsilon-1}+\Omega^{h}-\tilde{w}^{s} \phi \text { for } \hat{q}_{l, \min }>\hat{q} \geq \hat{q}_{h, \text { min }}
\end{aligned}
$$

which can be rewritten as

$$
K_{1} \Upsilon^{h}(\hat{q}) \hat{q}^{-1}+\frac{\partial \Upsilon^{h}(\hat{q})}{\partial \hat{q}}=K_{2} \hat{q}^{\varepsilon-2}+K_{3} \hat{q}^{-\frac{\Psi+g}{g}}-K_{4} \hat{q}^{-1}
$$

where

$$
\begin{aligned}
& K_{1} \equiv \frac{\Psi+\nu}{g}, K_{2} \equiv \frac{\Pi+\nu \xi_{4}}{g}, K_{3} \equiv \frac{\nu \xi_{5}}{g} \text { and } K_{4} \equiv \frac{\nu \xi_{6}+\tilde{w} \phi-\Omega^{h}}{g} \text { for } \hat{q} \geq \hat{q}_{l, \text { min }} \\
& K_{1} \equiv \frac{\Psi+\nu}{g}, K_{2} \equiv \frac{\Pi}{g}, K_{3} \equiv 0 \text { and } K_{4} \equiv \frac{\tilde{w} \phi-\Omega^{h}}{g} \text { for } \hat{q}_{l, \min }>\hat{q} \geq \hat{q}_{h, \text { min }}
\end{aligned}
$$

We first define the following equalities

$$
f(\hat{q}) \equiv K_{1} \hat{q}^{-1} \text { and } g(\hat{q}) \equiv K_{2} \hat{q}^{\varepsilon-2}+K_{3} \hat{q}^{-\frac{\Psi+g}{g}}-K_{4} \hat{q}^{-1}
$$


Then we can express the general solution as

$$
\begin{aligned}
\Upsilon^{h}(\hat{q}) & =\hat{q}^{-K_{1}}\left(\int\left[K_{2} \hat{q}^{K_{1}+\varepsilon-2}+K_{3} \hat{q}^{K_{1}-\frac{\Psi+g}{g}}-K_{4} \hat{q}^{K_{1}-1}\right] d \hat{q}+D\right) \\
& =\frac{K_{2} \hat{q}^{\varepsilon-1}}{K_{1}+\varepsilon-1}+\frac{K_{3} \hat{q}^{1-\frac{\Psi+g}{g}}}{K_{1}+1-\frac{\Psi+g}{g}}-\frac{K_{4}}{K_{1}}+D \hat{q}^{-K_{1}}
\end{aligned}
$$

To find the constant of integration $D$, we use $\Upsilon^{h}\left(\hat{q}_{h, \min }\right)=0$ :

$$
D=-\frac{K_{2} \hat{q}_{h, \min }^{K_{1}+\varepsilon-1}}{K_{1}+\varepsilon-1}-\frac{K_{3} \hat{q}_{h, \min }^{K_{1}+1-\frac{\Psi+g}{g}}}{K_{1}+1-\frac{\Psi+g}{g}}+\frac{K_{4} \hat{q}_{h, \min }^{K_{1}}}{K_{1}} \text { for } \hat{q} \in\left[\hat{q}_{h, \min }, \hat{q}_{l, \mathrm{~min}}\right]
$$

Then we can express the value function as

$$
\Upsilon^{h}(\hat{q})=\left\{\begin{array}{c}
\frac{K_{2} \hat{q}^{\varepsilon-1}}{K_{1}+\varepsilon-1}+\frac{K_{3} \hat{q}^{1-\frac{\Psi+g}{g}}}{K_{1}+1-\frac{\Psi+g}{g}}-\frac{K_{4}}{K_{1}} \\
+\left[\begin{array}{c}
K_{2} \hat{q}_{h, \min }^{\varepsilon-1} \\
K_{1}+\varepsilon-1
\end{array}-\frac{K_{3} \hat{q}_{h, \min }^{1-\frac{\Psi+g}{g}}}{K_{1}+1-\frac{\Psi+g}{g}}+\frac{K_{4}}{K_{1}}\right]\left(\frac{\hat{q}_{h, \min }}{\hat{q}}\right)^{K_{1}}
\end{array}\right\}=\left[\begin{array}{c}
\frac{K_{2} \hat{q}^{\varepsilon-1}}{K_{1}+\varepsilon-1}\left[1-\left(\frac{\hat{q}_{h, \min }}{\hat{q}}\right)^{K_{1}+\varepsilon-1}\right. \\
+\frac{K_{3} \hat{q}^{-\frac{\Psi}{g}}}{K_{1}-\frac{\Psi}{g}}\left[1-\left(\frac{\hat{q}_{h, \min }}{\hat{q}}\right)^{K_{1}-\frac{\Psi}{g}}\right. \\
-\frac{K_{4}}{K_{1}}\left[1-\left(\frac{\hat{q}_{h, \text { in }}}{\hat{q}}\right)^{K_{1}}\right.
\end{array}\right] .
$$

Hence

$$
\Upsilon^{h}(\hat{q})=\left[\begin{array}{c}
\frac{K_{2} \hat{q}^{\varepsilon-1}}{K_{1}+\varepsilon-1}\left[1-\left(\frac{\hat{q}_{h, \text { min }}}{\hat{q}}\right)^{K_{1}+\varepsilon-1}\right. \\
+\frac{K_{3} \hat{q}^{-\frac{\Psi}{g}}}{K_{1}-\frac{\Psi}{g}}\left[1-\left(\frac{\hat{q}_{h, \text { min }}}{\hat{q}}\right)^{K_{1}-\frac{\Psi}{g}}\right] \\
-\frac{K_{4}}{K_{1}}\left[1-\left(\frac{\hat{q}_{h, \min }}{\hat{q}}\right)^{K_{1}}\right]
\end{array}\right]
$$

Hence from (B-5), for $\hat{q} \in\left[\hat{q}_{h, \min }, \hat{q}_{l, \min }\right]$

$$
\Upsilon^{h}(\hat{q})=\left[\frac{\Pi \hat{q}^{\varepsilon-1}}{\Psi+\nu+(\varepsilon-1) g}\left[1-\left(\frac{\hat{q}_{h, \min }}{\hat{q}}\right)^{\frac{\Psi+\nu+(\varepsilon-1) g}{g}}\right]-\frac{\tilde{w} \phi-\Omega^{h}}{\Psi+\nu}\left[1-\left(\frac{\hat{q}_{h, \min }}{\hat{q}}\right)^{\frac{\Psi+\nu}{g}}\right]\right]
$$

This expression makes perfect sense because $\nu$ acts just like a destructive shock for $\hat{q} \in\left[\hat{q}_{h, \min }, \hat{q}_{l, \min }\right]$ and hence becomes part of the effective discount rate.

For $\hat{q} \geq \hat{q}_{l, \min }$, the appropriate values for $K \mathrm{~s}$ from (B-4) delivers (B-6) as

$$
\Upsilon^{h}(\hat{q})=\frac{\Pi \hat{q}^{\varepsilon-1}}{\Psi+(\varepsilon-1) g}\left[1-\left(\frac{\hat{q}_{l, \min }}{\hat{q}}\right)^{\frac{\Psi+(\varepsilon-1) g}{g}}\right]+\frac{\Omega^{l}-\tilde{w}^{s} \phi}{\Psi}\left[1-\left(\frac{\hat{q}_{l, \min }}{\hat{q}}\right)^{\frac{\Psi}{g}}\right]+\frac{\Omega^{h}-\Omega^{l}}{\Psi+\nu}+D \hat{q}^{-\frac{\Psi+\nu}{g}}
$$

Next we use the boundary condition. Note that

$$
\Upsilon^{h}\left(\hat{q}_{l, \text { min }}\right)=\frac{\Pi \hat{q}_{l, \text { min }}^{\varepsilon-1}}{\Psi+\nu+(\varepsilon-1) g}\left[1-\left(\frac{\hat{q}_{h, \text { min }}}{\hat{q}_{l, \text { min }}}\right)^{\frac{\Psi+\nu+(\varepsilon-1) g}{g}}\right]-\frac{\tilde{w} \phi-\Omega^{h}}{\Psi+\nu}\left[1-\left(\frac{\hat{q}_{h, \text { min }}}{\hat{q}_{l, \text { min }}}\right)^{\frac{\Psi+\nu}{g}}\right]
$$


Hence, the constant of integration for $\hat{q} \geq \hat{q}_{l, \min }$ must satisfy (B-7). Next using (B-4), $\Upsilon^{h}\left(\hat{q}_{l, \min }\right)$ for $\hat{q} \geq \hat{q}_{l, \min }$ is found as

$$
\begin{aligned}
\Upsilon^{h}\left(\hat{q}_{l, \text { min }}\right) & =\frac{K_{2} \hat{q}_{l, \text { min }}^{\varepsilon-1}}{K_{1}+\varepsilon-1}+\frac{K_{3} \hat{q}_{l, \text { min }}^{1-\frac{\Psi+g}{g}}}{K_{1}+1-\frac{\Psi+g}{g}}-\frac{K_{4}}{K_{1}}+D \hat{q}_{l, \text { min }}^{-K_{1}} \\
& =\frac{\left(\Pi+\nu \xi_{4}\right) \hat{q}_{l, \text { min }}^{\varepsilon-1}}{\Psi+\nu+g(\varepsilon-1)}+\xi_{5} \hat{q}_{l, \text { min }}^{-\frac{\Psi}{g}}-\frac{\nu \xi_{6}+\tilde{w} \phi-\Omega^{h}}{\Psi+\nu}+D \hat{q}_{l, \text { min }}^{-\frac{\Psi+\nu}{g}}
\end{aligned}
$$

which must be equal to (B-7). Equating (B-7) to (B-8) we get

$$
D=\left\{\begin{array}{c}
-\frac{\Pi}{\Psi+\nu+(\varepsilon-1) g} \hat{q}_{h, \min }^{\frac{\Psi+\nu+(\varepsilon-1) g}{g}}+\frac{\tilde{w} \phi-\Omega^{h}}{\Psi+\nu} \hat{q}_{h, \min }^{\frac{\Psi+\nu}{g}} \\
-\frac{\nu \xi_{4}}{\Psi+\nu+g(\varepsilon-1)} \hat{q}_{l, \min }^{\frac{\Psi+\nu+1) g}{g}}-\xi_{5} \hat{q}_{l, \text { min }}^{\frac{\nu}{g}}+\frac{\nu \xi_{6}}{\Psi+\nu} \hat{q}_{l, \text { min }}^{\frac{\Psi+\nu}{g}}
\end{array}\right\}
$$

Hence

$$
\hat{q}^{-\frac{\Psi+\nu}{g}} D=\left\{\begin{array}{c}
\frac{\Pi \hat{q}^{\varepsilon-1}}{\Psi+\nu+g(\varepsilon-1)}\left[1-\left(\frac{\hat{q}_{h, \min }}{\hat{q}}\right)^{\frac{\Psi+\nu+(\varepsilon-1) g}{g}}\right]-\frac{\Pi \hat{q}^{\varepsilon-1}}{\Psi+\nu+g(\varepsilon-1)}\left[1-\left(\frac{\hat{q}_{l, \min }}{\hat{q}}\right)^{\frac{\Psi+\nu+(\varepsilon-1) g}{g}}\right] \\
-\frac{\Omega^{l}-\Omega^{h}}{\Psi+\nu} \\
-\frac{\tilde{w} \phi-\Omega^{h}}{\Psi+\nu}\left[1-\left(\frac{\hat{q}_{h, \text { min }}}{\hat{q}}\right)^{\frac{\Psi+\nu}{g}}\right]+\frac{\tilde{w}^{s} \phi-\Omega^{l}}{\Psi+\nu}\left[1-\left(\frac{\hat{q}_{l, \min }}{\hat{q}}\right)^{\frac{\Psi+\nu}{g}}\right]
\end{array}\right\}
$$

Hence for $\hat{q} \geq \hat{q}_{l, \min }$

$$
\Upsilon^{h}(\hat{q})=\left\{\begin{array}{c}
\frac{\Pi \hat{q}^{\varepsilon-1}}{\Psi+\nu+g(\varepsilon-1)}\left[1-\left(\frac{\hat{q}_{h, \text { min }}}{\hat{q}}\right)^{\frac{\Psi+\nu+(\varepsilon-1) g}{g}}\right]+\frac{\Omega^{h}-\tilde{w} \phi}{\Psi+\nu}\left[1-\left(\frac{\hat{q}_{h, \text { min }}}{\hat{q}}\right)^{\frac{\Psi+\nu}{g}}\right] \\
\frac{\Pi \hat{q}^{\varepsilon-1}}{\Psi+(\varepsilon-1) g}\left[1-\left(\frac{\hat{q}_{l, \min }}{\hat{q}}\right)^{\frac{\Psi+(\varepsilon-1) g}{g}}\right]+\frac{\Omega^{l}-\tilde{w}^{s} \phi}{\Psi}\left[1-\left(\frac{\hat{q}_{l, \min }}{\hat{q}}\right)^{\frac{\Psi}{g}}\right] \\
-\left(\frac{\Pi \hat{q}^{\varepsilon-1}}{\Psi+\nu+g(\varepsilon-1)}\left[1-\left(\frac{\hat{q}_{l, \min }}{\hat{q}}\right)^{\frac{\Psi+\nu+(\varepsilon-1) g}{g}}\right]+\frac{\Omega^{l}-\tilde{w}^{s} \phi}{\Psi+\nu}\left[1-\left(\frac{\hat{q}_{l, \min }}{\hat{q}}\right)^{\frac{\Psi+\nu}{g}}\right]\right.
\end{array}\right\}
$$

Our next task is to find the values for $\hat{q}_{k \text {,min }}$. Using the above differential equations we get

$$
\left.\frac{\partial \Upsilon^{l}(\hat{q})}{\partial t}\right|_{\hat{q}=\hat{q}_{l, \text { min }}}=\frac{1}{g}\left[\Pi \hat{q}_{l, \text { min }}^{\varepsilon-2}+\frac{\Omega^{l}-\tilde{w}^{s} \phi}{\hat{q}_{l, \min }}\right]
$$

From the smooth-pasting condition we get

$$
\left.\frac{\partial \Upsilon^{l}(\hat{q})}{\partial \hat{q}}\right|_{\hat{q}=\hat{q}_{l, \text { min }}}=0 \Longrightarrow \hat{q}_{l, \min }=\left[\frac{\tilde{w}^{s} \phi-\Omega^{l}}{\Pi}\right]^{\frac{1}{\varepsilon-1}} .
$$

Similarly

$$
\left.\frac{\partial \Upsilon^{h}(\hat{q})}{\partial \hat{q}}\right|_{\hat{q}=\hat{q}_{h, \text { min }}}=\frac{\Pi}{\Psi+\nu+(\varepsilon-1) g}\left[(\varepsilon-1) \hat{q}^{\varepsilon-2}+\frac{\Psi+\nu}{g} \hat{q}_{h, \min }^{\frac{\Psi+\nu+(\varepsilon-1) g}{g}} \hat{q}^{-\frac{\Psi+\nu}{g}-1}\right]-\frac{\tilde{w} \phi-\Omega^{h}}{g} \hat{q}_{h, \min }^{\frac{\Psi+\nu}{g}} \hat{q}^{-\frac{\Psi+\nu}{g}-1}
$$

and $\left.\frac{\partial \Upsilon^{h}(\hat{q})}{\partial \hat{q}}\right|_{\hat{q}=\hat{q}_{h, \min }}=0$ implies

$$
\hat{q}_{h, \min }=\left[\frac{\tilde{w} \phi-\Omega^{h}}{\Pi}\right]^{\frac{1}{\varepsilon-1}}
$$




\section{Robustness Checks}

Here we present the results of the robustness checks discussed in the text, and the results of shutting off the selection effect, obtained by free estimating the model without firm-type heterogeneity.

Table B1. Uniform Firm Types $\theta^{H}=\theta^{L}=\bar{\theta}$

\begin{tabular}{cccccccccc}
\hline \hline \multicolumn{10}{c}{ PANEL A. BASELINE } \\
\hline$x^{\text {entry }}$ & $x$ & $m$ & $\Phi$ & $\hat{q}_{\text {min }}$ & $d r o p$ & $\frac{w^{s}}{w^{u}}$ & $\tau$ & $g$ & Wel \\
\hline 11.44 & 4.24 & 51.19 & 96.28 & 16.26 & 0.09 & 14.58 & 9.94 & 2.26 & 100.00 \\
\hline \hline & \multicolumn{10}{c}{ PANEL } & B. SOCIAL PLANNER \\
\hline 11.44 & 4.24 & 55.73 & 90.39 & 85.30 & 2.05 & n/a & 10.21 & 2.90 & 103.06 \\
\hline \hline
\end{tabular}

Table B2. Robustness Check with $\gamma=0.5(1 \%$ of GDP)

\begin{tabular}{|c|c|c|c|c|c|c|c|c|c|c|c|}
\hline \multicolumn{12}{|c|}{ PANEL A. BASELINE } \\
\hline$x^{\text {entry }}$ & $x^{l}$ & $x^{h}$ & $\Phi^{l}$ & $\Phi^{h}$ & $\hat{q}_{l, \min }$ & $\hat{q}_{h, \min }$ & $d r o p_{l}$ & $\frac{w^{s}}{w^{u}}$ & $\tau$ & $g$ & Wel \\
\hline 8.48 & 1.98 & 8.89 & 64.61 & 21.92 & 10.76 & 0.00 & 0.03 & 15.65 & 8.70 & 2.24 & 100.00 \\
\hline \multicolumn{12}{|c|}{ PANEL B. InCUMBENT R\&D SUbSidy $\left(s_{i}=11 \%\right)$} \\
\hline 8.48 & 2.21 & 10.19 & $\begin{array}{ll}58.45 & 63.41\end{array}$ & 22.78 & 10.39 & 0.00 & 0.03 & 15.93 & 8.68 & 2.24 & 99.88 \\
\hline \multicolumn{12}{|c|}{ PANEL C. Operation Subsidy $\left(s_{o}=7 \%\right)$} \\
\hline 8.48 & 1.98 & 8.90 & $64.54 \quad 64.38$ & 21.92 & 8.77 & 0.00 & 0.02 & 15.90 & 8.70 & 2.23 & 99.91 \\
\hline \multicolumn{12}{|c|}{ PAnel D. Entry Subsidy $\left(s_{e}=4 \%\right)$} \\
\hline 8.48 & 1.91 & 8.46 & 64.47 & 21.66 & 12.30 & 0.00 & 0.04 & 16.13 & 8.70 & 2.25 & 100.04 \\
\hline
\end{tabular}

Table B3. Optimal Policy with $\gamma=0.5$

PANEl A. Social PlanNer

\begin{tabular}{ccccccccccccc}
\hline$x^{\text {entry }}$ & $x^{l}$ & $x^{h}$ & $m$ & $\Phi^{l}$ & $\Phi^{h}$ & $\hat{q}_{l, \min }$ & $\hat{q}_{h, \mathrm{~min}}$ & $d r o p_{l}$ & $\frac{w^{s}}{w^{u}}$ & $\tau$ & $g$ & Wel \\
\hline 8.48 & 1.87 & 9.51 & 66.05 & 57.36 & 23.38 & 86.75 & 1.39 & 0.42 & $\mathrm{n} / \mathrm{a}$ & 8.90 & 2.86 & 102.0 \\
\hline \hline PANEL B. OPTIMAL INCUMBENT AND ENTRY POLICIES & $\left(s_{i}=13 \%, s_{o}=-180 \%, s_{e}=8 \%\right)$ \\
\hline \hline 8.48 & 2.11 & 9.28 & 64.76 & 59.90 & 22.39 & 76.37 & 36.04 & 0.03 & 12.05 & 8.83 & 2.69 & 101.7 \\
\hline \hline \multicolumn{8}{c}{ PANEL C. OPTIMAL INCUMBENT POLICIES $\left(s_{i}=5 \%, s_{o}=-205 \%\right)$} \\
\hline \hline 8.48 & 2.11 & 9.28 & 64.76 & 59.90 & 22.39 & 76.36 & 36.04 & 0.03 & 11.08 & 8.83 & 2.69 & 101.7 \\
\hline \hline
\end{tabular}

Table B4. Robustness Check with $\varrho=0(1 \%$ of GDP $)$

\begin{tabular}{ccccccccccccc}
\hline \hline \multicolumn{10}{c}{ PANEL A. BASELINE } \\
\hline$x^{\text {entry }}$ & $x^{l}$ & $x^{h}$ & $m$ & $\Phi^{l}$ & $\Phi^{h}$ & $\hat{q}_{l, \min }$ & $\hat{q}_{h, \text { min }}$ & $d r o p_{l}$ & $\frac{w^{s}}{w^{u}}$ & $\tau$ & $g$ & Wel \\
\hline 8.98 & 3.67 & 11.13 & 72.73 & 61.95 & 25.82 & 24.87 & 0.00 & 0.07 & 15.57 & 11.68 & 2.24 & 100.00 \\
\hline \hline \multicolumn{10}{c}{ PANEL B. InCUMBENT R\&D SuBSIDY $\left(s_{i}=15 \%\right)$} \\
\hline 8.98 & 3.92 & 12.01 & 67.81 & 61.54 & 26.23 & 24.30 & 0.00 & 0.07 & 15.85 & 11.65 & 2.23 & 99.86 \\
\hline \hline \multicolumn{10}{c}{ PANEL C. OPERATION SUBSIDY $\left(s_{o}=6 \%\right)$} \\
\hline 8.98 & 3.67 & 11.14 & 72.64 & 62.06 & 25.81 & 22.29 & 0.00 & 0.06 & 15.83 & 11.67 & 2.22 & 99.82 \\
\hline \hline 8.98 & 3.60 & 10.89 & 74.03 & 61.95 & 25.71 & 27.25 & 0.00 & 0.08 & 16.02 & 11.68 & 2.25 & 100.1 \\
\hline \hline
\end{tabular}


Table B5. Optimal Policy with $\varrho=0$

\begin{tabular}{|c|c|c|c|c|c|c|c|c|c|c|c|c|}
\hline \multicolumn{13}{|c|}{ Panel A. Social Planner } \\
\hline$x^{\text {entry }}$ & $x^{l}$ & $x^{h}$ & $m$ & $\Phi^{l}$ & $\Phi^{h}$ & $\hat{q}_{l, \min }$ & $\hat{q}_{h, \min }$ & $d r o p_{l}$ & $\frac{w^{s}}{w^{u}}$ & $\tau$ & $g$ & Wel \\
\hline 8.98 & 3.25 & 12.30 & 83.03 & 38.16 & 30.55 & 181 & 0.5 & 1.60 & $\mathrm{n} / \mathrm{a}$ & 12.45 & 5.10 & 111 \\
\hline \multicolumn{13}{|c|}{ Panel B. Optimal Incumbent and Entry Policies $\left(s_{i}=20 \%, s_{o}=-298 \%, s_{e}=4 \%\right)$} \\
\hline 8.98 & 4.02 & 11.97 & 73.55 & 53.08 & 26.86 & 129 & 79.0 & 0.88 & 9.10 & 11.95 & 3.30 & 105.9 \\
\hline \multicolumn{13}{|c|}{ Panel C. Optimal Incumbent Policies $\left(s_{i}=17 \%, s_{o}=-315 \%\right)$} \\
\hline 8.98 & 4.02 & 11.97 & 73.56 & 53.08 & 26.86 & 129 & 79.1 & 0.88 & 8.72 & 11.95 & 3.30 & 105.9 \\
\hline
\end{tabular}

Table B6. Robustness Check with Fixed Entrant Supply (1\% of GDP)

\begin{tabular}{|c|c|c|c|c|c|c|c|c|c|c|c|}
\hline \multicolumn{12}{|c|}{ PANEL A. BASELINE } \\
\hline$x^{\text {entry }}$ & $x^{l}$ & $x^{h}$ & $\Phi^{l}$ & $\Phi^{h}$ & $\hat{q}_{l, \min }$ & $\hat{q}_{h, \min }$ & $d r o p_{l}$ & $\frac{w^{s}}{w^{u}}$ & $\tau$ & $g$ & Wel \\
\hline 7.37 & 2.91 & 8.24 & 67.92 & 27.78 & 34.26 & 3.21 & 0.19 & 15.14 & 11.63 & 2.43 & 100.00 \\
\hline \multicolumn{12}{|c|}{ Panel B. Incumbent R\&D Subsidy $\left(s_{i}=17 \%\right)$} \\
\hline 6.98 & 3.16 & 9.01 & 67.73 & 27.63 & 37.42 & 3.37 & 0.22 & 16.16 & 11.61 & 2.44 & 100.05 \\
\hline \multicolumn{12}{|c|}{ Panel C. Operation Subsidy $\left(s_{o}=6 \%\right)$} \\
\hline 7.36 & 2.90 & 8.23 & 68.19 & 27.75 & 31.00 & 0.00 & 0.17 & 15.43 & 11.62 & 2.41 & 99.82 \\
\hline \multicolumn{12}{|c|}{ Panel D. Entry Subsidy $\left(s_{e}=11 \%\right)$} \\
\hline 7.61 & 2.75 & 7.77 & 67.54 & 27.87 & 38.85 & 10.38 & 0.23 & 15.91 & 11.63 & 2.45 & 100.12 \\
\hline
\end{tabular}

Table B7. Optimal Policy with Fixed Entrant Supply

\begin{tabular}{|c|c|c|c|c|c|c|c|c|c|c|c|}
\hline \multicolumn{12}{|c|}{ Panel A. Social Planner } \\
\hline$x^{e n t r y}$ & $x^{l}$ & $x^{h}$ & $\Phi^{l}$ & $\Phi^{h}$ & $q_{l, \text { min }}$ & $\hat{q}_{h, \min }$ & $d r o p_{l}$ & $\frac{w^{s}}{w^{u}}$ & $\tau$ & $g$ & Wel \\
\hline 7.78 & 2.88 & 8.98 & 56.7 & 29.8 & 89.57 & 4.68 & 0.79 & $\mathrm{n} / \mathrm{a}$ & 12.09 & 3.05 & 102.62 \\
\hline \multicolumn{12}{|c|}{ Panel B. Optimal InCUmbent And Entry Policies $\left(s_{i}=12 \%, s_{o}=-78 \%, s_{e}=7 \%\right)$} \\
\hline 7.41 & 3.06 & 8.66 & 64.05 & 28.14 & 71.28 & 44.58 & 0.54 & 13.17 & 11.80 & 2.66 & 101.16 \\
\hline \multicolumn{12}{|c|}{ Panel C. Optimal Incumbent Policies $\left(s_{i}=6 \%, s_{o}=-90 \%\right)$} \\
\hline 7.41 & 3.06 & 8.65 & 64.07 & 28.14 & 71.12 & 44.40 & 0.54 & 12.33 & 11.80 & 2.65 & 101.16 \\
\hline
\end{tabular}

